FACULdADE DE CIÊNCIAS ECONÔ MICAS DA UFRGS

MACROECONOMIA DO BRASIL PÓS-1994 LUIZ CARLOS BRESSER-PEREIRA

DESENVOLVIMENTO ECONOMMICO, PREFERÊNCIA PELA LIQUIDEZ E ACESSO BANCÁRIO: UM ESTUDO DE CASO DAS MESORREGIÓES DE MINAS GERAIS

MARCO CROCCO, CLAUDIO BARRA DE CASTRO, ANDERSON CAVALCANTE E VANESSA DA COSTA VAL

FRIEDMAN E O MONETARISMO: A VELHA TEORIA QUANTITATIVA DA MOEDA E A MODERNA ESCOLA MONETARISTA

GENTIL CORAZZAE RODRIGO L. KREMER

BOLLHAS RACIONAIS, CICLO DE PREÇOS DE ATIVOS E RACIONALIDADE LIMITADA: UMA AVALIACAOO CRITICA DOS MODELOS NEOCLÁSSICOS DE BOLHAS ESPECULATIVAS JOSÉ LUIS OREIRO

VULNERABILITY INDICATORS OF THE TWIN CRISES: THE EAST ASIAN EPISODE

TITO BELCHIOR SILVA MOREIRA

IMPACTOS POTENCIAIS DA NEGOCIAÇÃO DA ALCA SOBRE OS INVESTIMENTOS EXTERNOS EM SERVIÇOS PROFISSIONAIS NO BRASIL

MICHEL ALEXANDRE, OTAVIANO CANUTO E GILBERTO TADEU LIMA

TEORIA MARXISTA DO VALOR: UMA INTRODUÇẢO ALFREDO SAAD FILHO

UM ESTUDO EMPIRICO DOS CICLOS POLITICO. ECONOOMICOS NO BRASIL

ATHOS PRATES DA SILVEIRA PREUSSLER E MARCELO SAVINO PORTUGAL

RELENDO CHANDLER, WILLIAMSON E NORTH PARA ENTENDER O PROCESSO DE FORMACĀO DAS ESTRADAS DE FERRO NO BRASIL

JEFFERSON ANDRONIO RAMUNDO STADUTO

WEIMAR FREIRE DA ROCHA IR. E CLAIITON ATAIDES DE FREITAS

MATRIZ DE INSUMO-PRODUTO PARA A ECONOMIA TURISTICA BRASILEIRA: CONSTRUCCÃO E ANÁLISE DAS RELAÇÓES INTERSETORIAIS

FRANCISCO CASIMIRO FILHO E JOAQUIM JOSÉ MARTINS GUILHOTO

SEÇĀO ESPECIAL: AVALIAÇŌES INICIAIS DA POLITTICA ECONÓMICA DO GOVERNO LULA

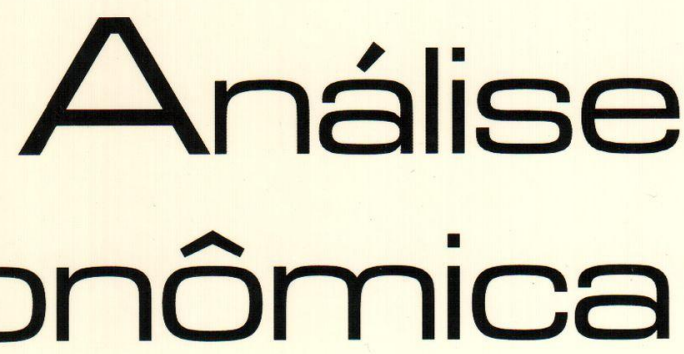


Universidade Federal do Rio Grande do Sul

Reitora: Profa. Wrana Maria Panizzi

Faculdade de Ciencias EConómicas

Diretora: Prof Pedro César Dutra Fonseca

Centro de Estudos e Pesquisas Economicas

Diretor: Prof. Gentil Corazza

Departamento de Ciéncias económicas

Chiefe: Prof. Ricardo Dathein

Curso de Pós. Graduação em Economia

Coordenador: Prof. Eduardo Pontual Ribeiro

Programa de Pós-Graduação em Desenvolvimento Rural

Coordenador: Prof. jalcione Almeida

CONSElHo EDITORIAL:

Carlos G. A. Mielitz Netto (UFRGS), Eduardo A. Maldonado Filho (UFRGS), Eduardo P. Ribeiro (UFRGS), Eleutério F. S. Prado (USP), Eugênio Lagemann (UFRGS), Fernando Cardim de Carvalho (UFRJ), Fernando Ferrari Filho (UFRGS), Fernando de Holanda Barbosa (FGV/RJ), Flávio Vasconcellos Comim (UFRGS), Gentil Corazza (UFRGS), Giácomo Balbinotto Netto (UFRGS), Gustavo Franco (PUC/RJ), Jan A. Kregel (UNCTAD), João Rogério Sanson (UFSC), Joaquim Pinto de Andrade (UnB), Jorge Paulo Araújo (UFRGS), Marcelo S. Portugal (UFRGS), Maria Alice Lahorgue (UFRGS), Paul Davidson (University of Tennessee), Paulo D. Waquil (UFRGS), Pedro C. D. Fonseca (UFRGS), Philip Arestis (Levy Economics Institut of Bard College), Roberto C. de Moraes (UFRGS), Ronald Otto Hillbrecht (UFRGS), Sabino da Silva Porto Jr. (UFRGS), Stefano Florissi (UFRGS) e Werner Baer (University of Illinois at UrbanaChampaign).

COMISSÃO EDITORIAL:

Eduardo Augusto Maldonado Filho, Fernando Ferrari Filho, Gentil Corazza, Marcelo Savino Portugal, Paulo Dabdab Waquil e Roberto Camps Moraes.

EDIroR: Prof. Fernando Ferrari Filho

Editor Adunnio: Prof. Gentil Corazza

SECRETÁrla: Clarissa Roncato Baldim

REVISÁO DE TEXTOS: Vanete Ricacheski

EDITORaÇão Eletrónica: Vanessa Hoffmann de Quadros

Fundador: Prof Antônio Carlos Santos Rosa

Os materiais publicados na revista Análise Econômica são da exclusiva responsabilidade dos autores. É permitida a reprodução total ou parcial dos trabalhos, desde que seja citada a fonte. Aceita-se permuta com revistas congêneres. Aceitam-se, também, livros para divulgação, elaboraçāo de resenhas e recensōes Toda correspondência, material para publicaçāo (vide normas na terceira capa), assinaturas e permutas devem ser dirigidos ao seguinte destinatário:

Análise Econômico

PROF FERNANDO FERRARI FILHO Revisła Análise Econômica - Av. João Pessoa, 52 CEP 90040-000 PORTO ALEGRE - RS, BRASL Telefones: (051) 316-3513 - Fax: (051) 316-3990 E-mail: rae@ufrgs.br

Ano 21, $n^{\circ} 39$, março, 2003 - Porto Alegre

Faculdade de Ciências Econômicas, UFRGS, 2003

Periodicidade semestral, março e setembro.

Tiragem: 500 exemplares

1. Teoria Econômica - Desenvolvimento Regional.

Economia Agrícola - Pesquisa Teórica e Aplicada -

Periódicos. I. Brasil

Faculdade de Ciências Econômicas,

Universidade Federal do Rio Grande do Sul 


\title{
Matriz de insumo-produto para a economia turística brasileira: construção e análise das relações intersetoriais
}

\author{
Francisco Casimiro Filho \\ Joaquim José Martins Guilhoto ${ }^{2}$
}

\begin{abstract}
This study aimed to analyze the tourism contributions to the Brazilian economy, considering the productive framework of 1999. For that, it was aimed to characterize the inter-sectors relations focusing on sectors that form the tourism segment. In order to perform this study, it was needed to share the input-output matrix constituted to the country into sectors which were considered touristy and non-touristy. In the analysis, it was used, the linkage index of Hirschmann-Rasmussem, the field of influence, the pure linkage. The linkages inter-sector indexes allowed the identification of key-sectors, considering the input-output model here developed and the level of aggregation used. Among the sectors classified as key-sectors, using the most extensive concept, six (06) were initially considered as compounds of the tourism segment: regular air transport, non-regular air transport, travel agents and agencies, supporting activities of air transport, hotels and other types of temporary accommodation, restaurants and other food establishments. In face of this, it is pointed out the importance of implementing policies and programs to promote the development of the sector of tourism in Brazil, considering that tourism contributes to the growth of the national economy.
\end{abstract}

Key-words: input-output, tourism, key-sectors JEL Classification: R15

\section{Introdução}

O turismo é um dos segmentos econômicos que mais têm crescido no mundo. Segundo a World Tourism Organization - WTO (2000), nos últimos anos ele vem apresentando crescimento médio de $7 \%$ ao ano, enquanto setores como agricultura e indústria vêm tendo crescimentos médios anuais de $2,3 \%$ e $3 \%$, respectivamente

\footnotetext{
${ }^{1}$ Prof. Assistente do Departamento de Ciências Econômicas e do Programa de Mestrado em Cultura e Turismo da Universidade Estadual de Santa Cruz - Ilhéus-BA.

${ }^{2}$ Prof Associado do Departamento de Economia, Administração e Sociologia da ESALQ/USP e do Regional Economics Laboratory (Real) da Universidade de Illinois (EUA).
} 
(World Bank, 2001). Com base nesse fato, alguns países atribuem a esse importante segmento econômico parte da tarefa de equilibrar e até obter superávit em suas balanças de serviços apenas com receitas advindas do turismo. Outros países, principalmente aqueles em desenvolvimento, analisam o turismo como uma das alternativas capazes de induzir melhoria na qualidade de vida de suas populações, ou seja, como uma atividade propulsora de desenvolvimento, gerando renda e emprego, principalmente em regiōes possuidoras de paisagens exóticas e com recursos financeiros escassos (Lopes, 1990). Uma das razōes para isso é o baixo nível relativo de investimentos requeridos para sua implantação, em comparação com qualquer outra indústria.

Desse modo, pode-se dizer que o turismo constitui uma possibilidade concreta de minimização das disparidades regionais entre as regiōes do país (Cruz, 2000). Assim, o turismo constitui alternativa capaz de fomentar o crescimento e o desenvolvimento regional. No entanto, apesar de reconhecer que o turismo exerce grande importância sobre a economia de determinado país, no Brasil existem poucos estudos que quantificam, com maior rigor, os impactos desse segmento sobre a economia, demonstrando, assim, a necessidade dé estudos sobre o turismo brasileiro, à luz de uma análise econômica.

Assim, torna-se necessário identificar e quantificar a contribuição dos setores que compõem o segmento do turismo relativamente aos demais setores da economia brasileira, sob a ótica de um modelo de insumo-produto para o ano de 1999, buscando verificar as relações intersetoriais estabelecidas, e, a partir daí, colaborar com os órgãos responsáveis pela elaboração e implementação de políticas econômicas que visam promover o crescimento nacional e, ou, regional, bem assim com o próprio turismo, no direcionamento de seus investimentos.

Além dessa parte introdutória, neste trabalho apresentam-se os procedimentos utilizados na construção do modelo de insumo-produto para o segmento do turismo no Brasil, bem como os conceitos e cálculos dos métodos de análise das relações intersetoriais na economia brasileira. Em seguida, apresentam-se e discutem-se os resultados obtidos a partir do modelo anteriormente referido. Por último, apresentam-se as considerações finais. 


\section{Referencial metodológico}

Para construir o modelo de insumo-produto da economia turística no Brasil, utilizou-se o método com informação censitária limitada, uma vez que as informações relacionadas com o segmento do turismo no Brasil são bastante escassas. Dessa forma, para construção do referido modelo, tomou-se como ponto de partida o modelo de insumo-produto geral da economia brasileira, elaborado por Guilhoto et al. (2001) para o ano de 1999, a partir das informações obtidas das Contas Nacionais do Brasil.

\subsection{A construção do modelo de insumo-produto do turismo no Brasil}

O modelo de insumo-produto geral para economia brasileira apresenta as informações numa abordagem do tipo enfoque produto por setor a preços básicos ${ }^{3}$, permitindo que cada produto seja produzido por mais de um setor e que cada setor produza mais de um produto, ou seja, existe uma matriz de produção e outra de uso dos insumos. A dimensão da matriz de produção é de 42 setores por 80 produtos e a matriz de uso, de 80 produtos por 42 setores.

A elaboração do modelo de insumo-produto para o turismo dar-se-á por meio da agregação de alguns setores (os que, segundo a literatura, têm pouca relação com o turismo) e da desagregação de outros setores (os que podem ser considerados de maior projeção turística).

Segundo Paci (1996), os termos setor turismo e produto turístico não existem no sentido econômico, pois o turismo é um conjunto de atividades econômicas (bens e serviços) que satisfazem as necessidades dos turistas, ou seja, o turismo compreende as atividades que as pessoas realizam durante suas viagens e estadas em lugares diferentes de sua residência por um tempo superior a 24 horas e inferior a um ano com fins de ócio, negócios e outros motivos (visitas a parentes e amigos, tratamento de saúde etc.). Excluem-se os trabalhadores das fronteiras, as viagens para estudos e para procurar emprego, os diplomatas e o pessoal das forças armadas quando em serviço.

${ }^{3}$ Preço básico é o preço de mercado dos bens e serviços menos os imposto indiretos líquidos e as margens de transporte e comercialização, ou seja, é o preço dos bens na porta da fábrica. 
Esse conjunto de atividades econômicas que compõem o segmento do turismo ainda não se encontra bem-definido na literatura, ou seja, não existe consenso entre os autores para definir quais atividades compōem esse segmento. Para Lage $\mathcal{E}$ Milone (1991), o conjunto de atividades econômicas que compõem o segmento do turismo são: transporte de passageiros (rodoviário, aéreo, marítimo, táxi), hospedagem (hotéis, pousadas, "flats"), alimentação (restaurantes, bares, lanchonetes), serviços culturais e de recreação (teatros, casas de espetáculos etc.). Já para Lundberg et al. (1995), os setores econômicos do turismo são: hotéis, restaurantes, transporte aéreo, aluguel de carros e agências de viagens. Vale salientar que os referidos autores, apesar de não apresentarem algumas atividades que foram citadas por outros autores, por exemplo Espanha (1996), não afirmaram que elas não poderiam ser incluídas no segmento do turismo.

Neste trabalho, a definição das atividades que foram utilizadas para compor o segmento do turismo foi feita, levando-se em consideração a definição dos autores anteriormente citados. Assim, as atividades econômicas que constituem o segmento do turismo foram reunidas em 12 setores do modelo de insumo-produto para o turismo no Brasil, a saber: Transporte rodoviário de passageiros, regular; Transporte rodoviário de passageiros, não-regular ${ }^{4}$; Transporte regular próprio para exploração de pontos turísticos; Transporte aéreo, regular; Transporte aéreo, não-regular ${ }^{5}$; Atividades de agências de viagens e organizadores de viagens; Atividades auxiliares do transporte terrestre ${ }^{6}$; Atividades auxiliares do transporte aéreo ${ }^{7}$; Estabelecimentos hoteleiros e outros tipos de alojamento temporário; Restaurantes e outros estabelecimentos de serviços de alimentação; Atividades recreativas, culturais e desportivas; e Aluguel de automóveis e outros meios de transporte.

\footnotetext{
${ }^{4}$ Inclui transporte escolar, de turismo e de pessoal de empresas.

${ }^{5}$ Inclui táxi aéreo, serviço de helicópteros e vôos fretados.

${ }^{6}$ Inclui exploraçāo de terminais rodoferroviários, parques de estacionamento e garagem, socorro e reboque, carga e descarga, agenciamento de cargas e guarda-volumes.

7 Inclui a exploração de aeroportos, campos de aterrissagem, de instalações de navegação, translado terrestre de passageiros, guarda-volumes e limpeza de aeronaves.
} 


\subsubsection{A abertura das matrizes de produção e uso dos insumos}

De acordo com o descrito no subitem anterior, nas tabelas de insumo-produto não é possível ter um setor de turismo, tendo em vista a heterogeneidade de atividades econômicas que compõem o segmento do turismo, em que se deveriam integrar bens e serviços totalmente distintos e incomparáveis, o qual violaria muitos princípios da contabilidade setorial (Briassoulis, 1991; Espanha, 1996). Assim, deve-se proceder algumas alterações na estrutura da matriz de insumo-produto do Brasil, buscando colocar em evidência as atividades de maior projeção turística, ou seja, transportes, serviços prestados às famílias e serviços prestados às empresas.

$\mathrm{Na}$ desagregação dos setores e dos produtos, procurou-se seguir a Classificação Internacional Uniforme das Atividades Turísticas (CIUAT) da OMT, bem como a Classificação Nacional de Atividades Econômicas (CNAE) do IBGE. Já a agregação dos setores foi feita levando-se em consideração o grau de homogeneidade das atividades de cada um.

$\mathrm{Na}$ desagregação dos setores (desagregação das linhas) da matriz de produção, utilizou-se como informaçōes básicas a participação relativa da receita bruta total de cada "subsetor" na receita bruta total do setor, obtidas em IBGE (1997), conforme apresentado a seguir.

O valor total da produção do setor de transportes foi distribuído entre os subsetores de acordo com a participação de cada um no valor total da produção do setor, ou seja: Transporte rodoviário de passageiros, regular $(0,217)$; Transporte rodoviário de passageiros, nāo-regular $(0,016)$; Transporte regular para expl. de pontos turísticos $(0,000)$; Transporte rodoviário de cargas $(0,343)$; Outros transportes terrestres $(0,055)$; Transporte aquaviário $(0,033)$; Transporte aéreo, regular $(0,178)$; Transporte aéreo, não-regular(0,010); Agências de viagens e organizadores de viagens $(0,049)$; Atividades auxiliares do transporte terrestre $(0,016)$; Atividades auxiliares do transporte aquaviário $(0,024)$; Atividades auxiliares do transporte aéreo (0,013); e Outras atividades auxiliares do transporte $(0,045)$.

Para o setor de Serviços prestados às famílias, o procedimento foi o seguinte: inicialmente, esse setor foi dividido em dois novos setores: - Alojamento e alimentação $(0,3127)$; e - Outros serviços $(0,6829)$, levando-se em consideração a participação dos novos setores no setor de Serviços prestados às famílias. Em seguida, proce- 
deu-se a uma nova desagregação de cada um dos dois novos setores. $\mathrm{O}$ setor de Alojamento e alimentação foi desagregado em Estabelecimentos hoteleiros e outros tipos de alojamento temporário $(0,2215)$; e em Restaurantes e outros estabelecimento de serviços de alimentação $(0,7785)$. O setor de Outros serviços foi desagregado em dois novos setores: Serviços recreativos, culturais e desportivos $(0,217)$; e Outros serviços prestados às famílias $(0,783)$. Esse procedimento foi adotado em virtude da maneira como os dados para desagregação estavam disponíveis.

Já o setor Serviços prestados às empresas foi desagregado, de forma semelhante à do setor de Transporte, em dois novos setores: Aluguel de automóveis e outros meios de transportes $(0,01)$; e Outros serviços prestados às empresas $(0,99)$.

Para realizar as desagregações descritas, observou-se a matriz de produção geral da economia brasileira, procurando identificar quais os produtos produzidos por cada um dos setores que foram desagregados, bem como a participação destes na produção total do setor. Uma vez encontradas as referidas participaçōes na produção dos setores, escolheu-se o produto com maior participação na produção do setor para desagregá-lo, considerando que cada um dos produtos desagregados era produzido somente por um setor. Os outros produtos produzidos pelos setores não foram desagregados, apenas distribuídos nos "subsetores", levando-se em consideração sua participação na produção.

Verificou-se também que os produtos de maior projeção turística eram produzidos por outros setores e não somente pelos setores turísticos. Assim, deveria ser feita uma distribuição desses produtos para os correspondentes produtos desagregados, a qual foi feita levando-se em consideração a participação na produção total do setor.

$\mathrm{Na}$ desagregação da matriz de uso partiu-se da tabela de uso geral da economia brasileira elaborada por Guilhoto et al. (2001). Inicialmente, separaram-se os setores que foram desagregados na matriz de produção, ou seja, Transportes, Serviços prestados às famílias e Serviços prestados às empresas.

Analisando as matrizes de uso que foram construídas para a economia brasileira, verificou-se que a matriz de uso para o ano de 1980 era a que mais se aproximava da desagregação pretendida no presente trabalho. Assim, optou-se por utilizar a participação do uso dos produtos utilizados como insumos no processo produtivo de cada setor, em 1980, para fazer a desagregação dos mesmos na ma- 
triz de uso para o ano de 1999. Isso foi possível, visto que se assumiu que não houve grandes modificações na estrutura dos transportes no Brasil, considerando do ano de 1980 até o ano de 1999.

Em seguida, procedeu-se a uma compatibilização das classificações de atividades e produtos em 1980 e 1999, de acordo com IBGE (1997a).

Os procedimentos utilizados na distribuição dos produtos dentro de cada um dos setores desagregados, bem como os utilizados na desagregação dos produtos, são descritos a seguir.

Setor de Transporte

A desagregação do setor de Transportes na matriz de uso dos insumos de 1980 é a que se segue: Transporte rodoviário, Transporte ferroviário, Transporte marítimo e Transporte aéreo.

Em cada um dos vetores anteriormente referidos foi feita uma desagregação do produto transportes, a fim de compatibilizá-lo com a matriz de uso de 1980 (nesta "abertura" do setor, considerou-se a participação dos produtos no produto total, informação obtida na matriz de produção). De posse dos vetores-coluna dos setores dos transportes da matriz de uso de 1980, calculou-se um coeficiente de distribuição da produção do setor para cada produto:

$\operatorname{Coef}_{i j}=\frac{x_{i j}}{V P_{j}}(j=$ rodoviário, ferroviário, marítimo e aéreo)

em que $X_{i j}$ é o produto $i$ usado como insumo no processo produtivo do setor $j$ e $V P_{j}$, o valor da produção do setor $j$.

Em seguida, distribuiu-se o valor da produção total do setor $j$ (obtido anteriormente na matriz de produção) no ano de 1999, levando em consideração os coeficientes de distribuição calculados anteriormente, isto é, o valor da produção total do setor j, em 1999 , foi multiplicado por cada um dos coeficientes de distribuição dos produtos.

$$
\text { Coef }_{i j} \times V P_{j 99}
$$

Uma vez distribuídos os valores dos produtos entre os setores (Transporte rodoviário, Transporte ferroviário, Transporte marítimo e Transporte aéreo), somaram-se as linhas (estes valores deveriam ser iguais aos dos produtos usados como insumo pelo setor de transporte em 1999). Dos valores encontrados nessas somas, subtraíramse os valores dos produtos usados como insumo pelo setor de Transportes. 
Essa diferença de cada um dos produtos foi, em seguida, distribuída entre os setores Transporte rodoviário, Transporte ferroviário, Transporte marítimo e Transporte aéreo, considerando-se, agora, a participação da produção dos mesmos na produção total do setor de Transportes em 1999 (0,5926; 0,1005; 0,0568; e 0,2501, respectivamente). Se a diferença fosse positiva, então deveria diminuir o produto usado como insumo pelo setor o equivalente à participação do setor na produção; se negativa, deveria acrescentar o produto a cada setor o equivalente à sua participação na produção.

A abertura dos setores e produtos explicitados anteriormente ainda não foi suficiente para que os objetivos do trabalho fossem totalmente atingidos. Assim, os setores foram desagregados, levando-se em consideração a sua participação na produção em:

$(1,00)$

- Transporte ferroviário

$(1,00)$

- Transporte hidroviário

$(1,00)$

- Transporte aéreo

$(1,00)$
- Transporte rodov. de passageiros, regular $(0,3662)$

- Transp. rodov de passageiros, não-regular $(0,0267)$

$\{$ - Transp. regular próprio para exploração de pontos turísticos $(0,0003)$

- Transporte rodoviário de cargas $(0,5793)$

- Atividades auxiliares do transp. terrestre $(0,0275)$

$\{$ - Outros transportes terrestres $(0,5515)$

$\{$ - Outras atividades auxiliares do transporte $(0,4485)$

$\{$ - Transporte aquaviário $(0,5812)$

$\{$ - Ativ auxiliares do transporte aquaviário $(0,4188)$

C - Transporte aéreo, regular $(0,7112)$

- Transporte aéreo, não-regular $(0,0398)$

- Agências e organizadores de viagens $(0,1962)$

- Ativ auxiliares do transporte aéreo $(0,0528)$

Como era esperado, além do setor de Transportes, outros setores da economia também utilizavam o produto Margem de transporte no seu processo produtivo. Assim, os novos produtos Margem de transporte deveriam ser distribuídos nos demais setores econômicos. No entanto, no caso do Brasil não foi encontrada nenhuma informação relacionada com a utilização do produto Margem de transportes pelos demais setores produtivos que pudesse ser utilizada nessa desagregação. Assim, dada a inexistência dessas informações, partiu-se para a utilização de informaçōes de modelos de insumo-produto construídos para outros países.

Após uma revisão de literatura e análise da Tabela Intersetorial da Economia Turística - TIOT-92 para a Espanha, constatou-se que, em termos de participação, a estrutura do setor de Transportes da Espanha era semelhante à do Brasil. Dessa forma, o produto Mar- 
gem de transporte foi distribuído nos diversos setores econômicos, considerando-se a mesma participação da TIOT-92.

No entanto, os produtos ainda não estavam desagregados de forma conveniente com a matriz de produção considerada neste trabalho, tendo a necessidade de desagregar novamente os seguintes produtos: Transporte rodoviário de passageiros, Transporte aéreo e Serviços anexos aos transportes. A "abertura" e distribuição dos valores desses produtos para os setores da economia foram feitas considerando a participação de cada um dentro do produto relacionado, de acordo com o observado na matriz de produção.

A desagregação desses produtos, bem como a participação dos "novos" produtos, é apresentada a seguir:

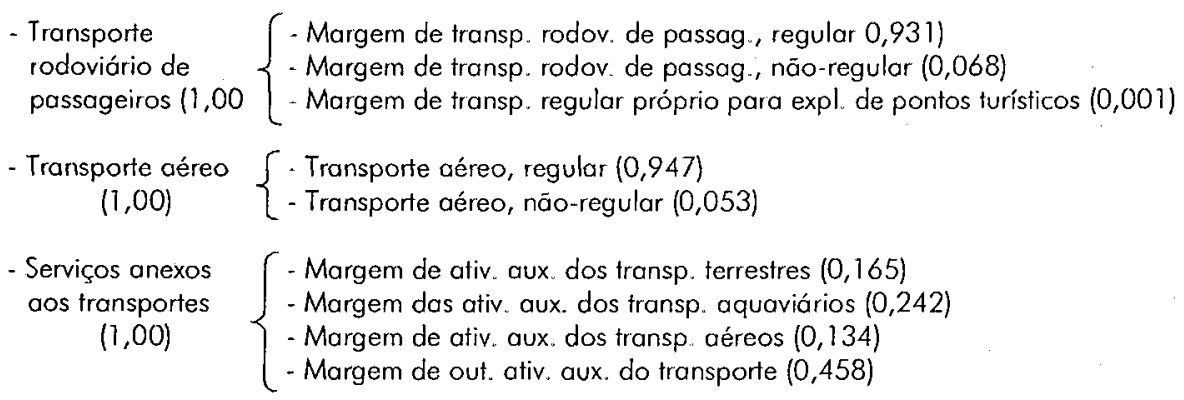

Serviços prestados às famílias

Tomando por base a matriz de uso dos insumos para o ano de 1980, construída para a economia brasileira pelo IBGE (IBGE, 1989), calculou-se a participação de cada insumo no valor da produção dos seguintes setores: Alojamento e alimentação e Outros serviços.

Em seguida, distribuíram-se os valores dos insumos em 1999, da seguinte maneira: em cada um dos vetores anteriormente referidos foi feita uma desagregação do produto Serviços prestados às famílias, a fim de compatibilizá-la com a matriz de uso de 1980 (nessa "abertura" do setor, considerou-se a participação dos produtos no produto total, informação obtida na matriz de produção). De posse do vetor-coluna do setor de Serviços prestados às famílias da matriz de uso de 1980, calculou-se um coeficiente de distribuição da produção do setor para cada produto:

$$
\operatorname{Coef}_{i j}=\frac{x_{i j}}{V P_{j}}(j=\text { Alojamento e alimentação e Outros serviços })
$$

em que $X_{i j}$ é o produto $i$ usado como insumo no processo produtivo do setor $\mathrm{j}$, e $V P_{j}$, o valor da produção do setor $j$. 
Em seguida, distribuiu-se o valor da produção total do setor $j$ (obtido anteriormente na matriz de produção), no ano de 1999, levando em consideração os coeficientes de distribuição calculados anteriormente, isto é, o valor da produção total do setor $j$, no ano de 1999, foi multiplicado por cada um dos coeficientes de distribuição dos produtos, ou seja:

\section{Coef $_{i j} \times V P_{j g 9}$}

Uma vez distribuídos os valores dos produtos entre os setores (Alojamento e alimentação e Outros serviços), os quais foram somados nas linhas (estes valores deveriam ser iguais aos dos produtos usados como insumos pelo setor de Serviços prestados às famílias em 1999). Dos valores encontrados nessa soma, subtraíram-se os valores dos produtos usados como insumos pelo setor de Serviços prestados às famílias. Essa diferença deveria ser nula, no entanto, na maioria dos casos, isso não foi verdadeiro, encontrando-se valores positivos e negativos. Ainda, a diferença de cada um dos produtos foi em seguida distribuída entre os setores Alojamento e alimentação e Outros serviços, considerando-se agora a participação da produção dos mesmos na produção total do setor de Serviços prestados às famílias em $1999(0,3423$ e 0,6577, respectivamente). Se essa diferença fosse positiva, então deveria ser diminuído o produto usado como insumo pelo setor o equivalente à participação do setor na produção; se fosse negativa, deveria ser acrescentado o produto a cada setor o equivalente à participação deste na produção.

A abertura, anteriormente referida, dos setores e produtos ainda não era suficiente para que os objetivos deste trabalho fossem atingidos. Assim, os setores foram novamente desagregados, levando-se em consideração a participação na produção em: Estabelecimentos hoteleiros e outros tipos de alojamento temporário $(0,2215)$ e Restaurantes e outros estabelecimentos de serviços de alimentação $(0,7785)$. Já o setor de Outros serviços foi desagregado em: Atividades recreativas, culturais e desportivas $(0,1011)$ e Outros serviços prestados às famílias $(0,8989)$. As referidas desagregações foram feitas de acordo com a participação no valor da produção das atividades, obtidas na matriz de produção calculada anteriormente.

O produto Serviços de alojamento e alimentação foi desagregado em: Estabelecimentos hoteleiros e outros tipos de alojamento temporário $(0,2215)$ e Restaurantes e outros estabelecimentos de serviços de alimentação $(0,7785)$. O produto Outros serviços foi desagregado em: Atividades recreativas, culturais e desportivas $(0,5245)$ 
e Outros serviços prestados às famílias $(0,4755)$. A "abertura" e distribuição dos valores destes produtos nos setores da economia foram feitas considerando a participação na produção, conforme a matriz de produção.

Vale ressaltar que as hipóteses assumidas para o setor de Serviços prestados às famílias foram as mesmas assumidas na construção da TIOT-92.

\section{Serviços prestados às empresas}

Com relação ao produto Serviços prestados às empresas, não foi encontrada em nenhuma outra matriz de uso dos insumos previamente construída, informação no nível de desagregação pretendida para o presente trabalho. Dessa forma, a "abertura" deste produto ocorreu de forma diferente da dos dois produtos descritos anteriormente.

$\mathrm{Da}$ matriz de produção, retirou-se a produção dos setores Aluguel de automóveis e outros meios de transporte e Outros serviços prestados às empresas, bem como a participação $(0,015)$ e $(0,985)$, respectivamente, desses dois setores na produção do setor de Serviços prestados às empresas. De posse dos vetores-coluna dos dois setores, fez-se a distribuição dos insumos em cada um deles, levando em consideração a sua participação na produção.

É importante ressaltar que todos os procedimentos utilizados até aqui decorreram do fato da inexistência de um conjunto de informações relacionado com a utilização de insumos pelos setores produtivos da economia brasileira, mais especificamente dos insumos e setores que compōem o segmento do turismo. Para que isso se torne possível, recomenda-se a realização de uma pesquisa aqui no Brasil, de modo que se possa conhecer com uma melhor exatidão o uso dos insumos na estrutura produtiva.

A desagregação de setores e produtos nas matrizes de uso e produção utilizadas na construção do modelo de insumo-produto para a economia turística no Brasil gerou algumas divergências nos valores das referidas matrizes. Para solucionar esse problema, lançou-se mão da técnica de balanceamento de matrizes conhecida na literatura como RAS .

\footnotetext{
${ }^{8}$ Para uma descrição detalhada do método RAS, ver, por exemplo, Miller e Blair (1985).
} 


\subsection{Obtenção da matriz de coeficientes técnicos para o segmento do turismo}

Para se chegar ao modelo de insumo-produto da economia turística, no presente estudo, partiu-se das matrizes de produção e uso dos insumos que foram estimadas anteriormente.

A tabela de produção nacional, da qual se origina a tabela $V_{(\mathrm{s} \times \mathrm{p})}$, fornece informações sobre a origem setorial dos bens e serviços produzidos em determinado ano na economia. As linhas indicam em quais setores os produtos são produzidos, enquanto as colunas indicam a origem setorial dos produtos. Na tabela de uso nacional da qual provém a tabela de uso $U_{(p \times s)}$, mostram-se, nas linhas, os produtos oferecidos para cada setor e, nas colunas, os demandados em cada setor da economia.

De acordo com Miller 83 Blair (1985), para se obter a matriz de Leontief, é preciso, então, utilizar as matrizes $V$ e $U$ que estão disponíveis, conforme descrito nos parágrafos subseqüentes.

Com base na tabela $U$ e no vetor $X_{\left(\mathrm{s}_{\mathrm{i} i}\right)}$, este último representando a produção nacional por setor, pode-se calcular a matriz $G_{(p \times s)}$ da seguinte forma:

$$
\mathrm{G}=\mathrm{U}(\hat{\mathrm{X}})^{-1}
$$

em que $G_{(\mathrm{p} x \mathrm{~s})}$ é a matriz nacional dos coeficientes técnicos dos insumos domésticos por setor e $(\hat{\boldsymbol{X}})^{-1}$, o vetor $X$ diagonalizado e invertido.

Com base na tabela $V$ e no vetor $Q_{(1 \times p)}^{\prime}$, este último representando a produção nacional por produto, pode-se calcular $D_{(\mathrm{s} x \mathrm{p})}$, dada por

$$
\mathrm{D}=\mathrm{V}\left(\hat{\mathrm{Q}}^{\prime}\right)^{-1}
$$

em que $D_{(\mathrm{s} \times \mathrm{p})}$ é a matriz de coeficientes técnicos de produto $\mathrm{e}$ $\left(\hat{Q}^{\prime}\right)^{-1}$, o vetor $Q$ diagonalizado e invertido. Finalmente, a matriz $A_{(s \times s)}$ dos coeficiente técnicos dos insumos diretos pode ser estimada por

$$
\mathrm{A}=\mathrm{DG}
$$

A expressão (3) traz implícita a hipótese adotada nesta tese, que é a da tecnologia baseada na indústria sob o enfoque setor $\mathrm{x}$ setor. Tal enfoque é usado na grande maioria dos estudos que utilizam a análise de insumo-produto, por permitir que se diferencie a tecnologia empregada na produção dos diversos produtos. 
A partir da matriz A, pode-se obter a matriz dos coeficientes técnicos de insumos diretos e indiretos para o turismo, ou matriz inversa de Leontief para o turismo, $B_{(s \times s)}$, da seguinte maneira:

$$
B=(I-A)^{-1}
$$

Essa matriz é também chamada de matriz dos impactos diretos e indiretos, por permitir verificar o impacto na produção, renda e emprego de uma variação na demanda final.

\subsection{Conceitos e cálculos dos métodos de análise das rela- ções intersetoriais na economia turística brasileira}

2.3.1 Índices de ligações de Hirschman-Rasmussen

Com o objetivo de efetuar o cálculo dos índices de ligaçōes tanto para frente como para trás de Hirschman-Rasmussen, deve-se tomar por base a expressão (4); definindo-se $b_{i j}$ como um elemento dessa matriz, $B^{*}$ como a média de todos os elementos da matriz $B$ e $B_{*_{j}}$ e $B_{i}$ como, respectivamente, a soma de uma coluna e de uma linha da matriz $B$.

Seguindo Guilhoto et al. (1994), os cálculos dos índices de ligações de Hirschman-Rasmussen são determinados da seguinte forma:

Índices de ligações para trás

$$
U_{j}=\frac{\left[\begin{array}{c}
B_{*_{j}} / n \\
n
\end{array}\right]}{B^{*}}
$$

Índices de ligações para frente

$$
U_{i}=\frac{\left[B_{i^{*}} / n\right]}{B^{*}}
$$

Os índices de Hirschman-Rasmussen indicam o grau de encadeamento dos setores da economia, tanto para trás como para frente, ou seja, evidenciam o grau com que um setor demanda ou oferta insumos para os demais setores do sistema econômico.

\subsubsection{O índice de dispersão}

Os índices de ligações para frente e para trás refletem, respectivamente, as forças de oferta e demanda de dado setor, e o índice de dispersão pode ser considerado um indicador de distribuição dessas forças. Assim, conforme apresentado por Bulmer-Thomas (1982), este índice complementa os índices de ligaçōes para frente e para 
trás de Hirschman-Rasmussen, à medida que possibilita interpretar como um impacto setorial distribui-se para outros setores.

As dispersões dos índices de ligações para trás e para frente são, segundo Bulmer-Thomas (1982), determinadas pelas seguintes expressōes:

Dispersão do índice de ligação - Dispersāo do índice de ligação

$$
V_{j}=\frac{\sqrt{\frac{\sum_{i}^{n}\left(b_{i j}-\frac{B_{* j}}{n}\right)^{2}}{n-1}}}{\frac{B_{* j}}{n}}
$$

para frente

A ocorrência de um baixo valor para determinada dispersão do índice de ligaçāo para trás significa que o impacto de uma variação da produção em determinado setor tende a estimular os demais setores de maneira uniforme. No caso de um alto índice de dispersão, isso significa que o impacto vai-se concentrar em poucos setores. Para o caso da dispersāo do índice de ligação para frente, um valor alto significa que a demanda por esse setor será concentrada em poucos setores, enquanto valor baixo significa que esse setor é demandado de maneira uniforme.

\subsubsection{Campo de influência}

Os índices de Hirschman-Rasmussen avaliam a importância de um setor em termos de seu impacto no sistema como um todo sem, contudo, identificar os principais elos dentro da economia, ou seja, sem identificar quais os coeficientes que, ao serem alterados, teriam maior impacto econômico como um todo. Essa deficiência dos índices de ligações pode ser suprida pela abordagem do campo de influência.

O conceito de campo de influência, segundo Sonis e Hewings (1989 e 1995), permite conhecer como as mudanças nos coeficientes técnicos se distribuem no sistema como um todo, ou seja, quais as relações entre os setores que teriam maior importância dentro do processo produtivo. Assim, o campo de influência pode ser compreendido como uma análise complementar à análise dos índices de ligação para frente e para trás de Hirschman-Rasmussen. 
Segundo Guilhoto et al. (1994) e Sonis e Hewings (1995), o procedimento para obtenção do campo de influência requer: a matriz dos coeficientes técnicos de produção, $\boldsymbol{A}=\left|a_{i j}\right|$; uma matriz de variações incrementais nos coeficientes diretos de insumo ou matriz de erro, $\boldsymbol{E}=\left|\varepsilon_{i j}\right|$; e as correspondentes matrizes inversas de Leontief dadas por $\boldsymbol{B}=\left|b_{i j}\right|$ e $\boldsymbol{B}(\varepsilon)=\left|b_{i j}(\varepsilon)\right|=|\boldsymbol{I}-\boldsymbol{A}-\varepsilon|^{-1}$.

Segundo Sonis e Hewings (1989 e 1995), admitindo-se uma variação muito pequena que só ocorre em um coeficiente direto, isto é:

$$
\varepsilon_{i j}=\left\{\begin{array}{lll}
\varepsilon & \text { para } & i=i_{1}, \quad j=j_{1} \\
0 & \text { para } & i \neq i_{1}, \quad j \neq j_{1}
\end{array}\right.
$$

Se $B-B(\varepsilon)$ corresponde ao impacto resultante da alteração nos coeficientes diretos, para cada coeficiente tem-se uma matriz de alterações ou matriz do campo de influência do coeficiente $a_{i j}$, dado pela expressão

$$
F\left(\varepsilon_{i j}\right)=\frac{\left\lfloor B\left(\varepsilon_{i j}\right)-B\right\rfloor}{\varepsilon_{i j}}
$$

em que $\boldsymbol{F}\left(\varepsilon_{i j}\right)$ é uma matriz do campo de influência do coeficiente $a_{i,}$, com dimensão $(n \times n)$.

O valor atribuído a cada matriz $\boldsymbol{F}\left(\varepsilon_{i j}\right)$ permite que se determinem quais os coeficientes que possuem o maior campo de influência. Dessa forma, esse valor é definido por

$$
S_{i j}=\sum_{k=1}^{n} \sum_{l=1}^{n}\left[f_{i}\left(\varepsilon_{i j}\right)\right]^{2}
$$

Os coeficientes diretos que possuírem os maiores valores de $S_{i j}$ serão aqueles com maior campo de influência na economia como um todo, ou seja, aqueles que produzem maior impacto.

\subsection{4 Índices puros de ligação}

Os índices de ligações sugeridos por Hirschman-Rasmussen apresentam a desvantagem de não considerar os diferentes níveis de produção de cada setor da economia. Com o objetivo de suprir essa desvantagem, vêm surgindo diferentes abordagens para o cálculo de índices de ligaçóes intersetoriais de uma economia, dentre eles, o do índice puro de ligação. 
Segundo Guilhoto et al. (1994) e Guilhoto et al. (1996), esse índice de ligação permite isolar dado setor $j$ do restante da economia, de forma a determinar o efeito das ligações totais do setor $j$ na economia. Em outras palavras, o índice puro de ligações indica a diferença entre a produção total na economia e a produção na economia se o setor $j$ não comprasse insumos do resto da economia nem vendesse sua produção para o restante desta.

Esses mesmo autores desenvolveram procedimentos que objetivaram aferir a relevância de dado setor para a economia, relativo ao valor da produção gerado por esse setor. Para isso, torna-se necessário decompor a matriz de coeficientes diretos de Leontief $(A)$, da seguinte forma:

$$
A=\left[\begin{array}{ll}
A_{i j} & A_{j r} \\
A_{r j} & A_{r r}
\end{array}\right]=\left[\begin{array}{ll}
A_{j j} & A_{j r} \\
A_{r j} & 0
\end{array}\right]+\left[\begin{array}{cc}
0 & 0 \\
0 & A_{r r}
\end{array}\right]=A_{j}+A_{r}
$$

em que $A_{i j}$ é a matriz de insumos diretos dentro do setor $j ; A_{r j}$ é a matriz de insumos diretos que o setor $j$ adquire do resto da economia; $A_{j r}$ é a matriz de insumos diretos que o resto da economia adquire do setor $j ; A_{r r}$ é a matriz de insumos diretos dentro do resto da economia; $A_{j}$ refere-se ao setor $j$ isolado do resto da economia; e $A_{r}$ representa o restante da economia.

$$
\left.\mathbf{B}=(\mathbf{I}-\mathbf{A})^{-1}=\left(\begin{array}{ll}
\mathbf{B}_{\mathrm{jj}} & \mathbf{B}_{\mathrm{jr}} \\
\mathbf{B}_{\mathrm{rj}} & \mathbf{B}_{\mathrm{rr}}
\end{array}\right)=\left(\begin{array}{cc}
\boldsymbol{\Delta}_{\mathrm{jj}} & \mathbf{0} \\
\mathbf{0} & \Delta_{\mathrm{rr}}
\end{array}\right)\left(\begin{array}{cc}
\boldsymbol{\Delta}_{\mathrm{j}} & \mathbf{0} \\
\mathbf{0} & \boldsymbol{\Delta}_{\mathrm{r}}
\end{array}\right) \begin{array}{cc}
\mathbf{I} & \mathbf{A}_{\mathrm{jr}} \boldsymbol{\Delta}_{\mathrm{r}} \\
\mathbf{A}_{\mathrm{rj}} \boldsymbol{\Delta}_{\mathrm{j}} & \mathbf{I}
\end{array}\right)
$$

Seguindo a abordagem de Guilhoto et al. (1996), a partir da expressão (10) se pode chegar a

em que os elementos da expressão (11) são assim definidos:

$\Delta_{j}=\left(\boldsymbol{I}-\boldsymbol{A}_{j j}{ }^{\gamma-1}\right.$ representa a interação do setor $j \mathrm{com}$ ele mesmo;

$\Delta_{r}=\left(\boldsymbol{I}-\boldsymbol{A}_{r r}{ }^{l-1}\right.$ representa a interação do restante da economia com ele mesmo;

$\Delta_{j j}=\left(\boldsymbol{I}-\Delta_{j} \boldsymbol{A}_{j r} \Delta_{r} \boldsymbol{A}_{r j}\right)^{-1}$ representa quanto o setor $j$ tem que produzir para o restante da economia para que ela atenda às suas necessidades; $\mathrm{e}$

$\Delta_{r r}=\left(\boldsymbol{I}-\Delta_{r} \boldsymbol{A}_{r j} \Delta_{j} \boldsymbol{A}_{j r}\right)^{-1}$ representa quanto o restante da economia vai ter que produzir para o setor $j$ para que ele atenda às suas necessidades.

Considerando as informaçōes contidas na expressão (11) e usando a formulação de Leontief dada por $X=(I-A)^{-1} Y$, expressão (12), 
é possível derivar um conjunto de índices de ligaçōes que permitam ordenar os setores em termos de importância do valor, bem como analisar como se verifica o processo de produção na economia.

Substituindo a expressão (11) na expressão (14), tem-se

$$
\left(\begin{array}{l}
X_{\mathrm{j}} \\
X_{r}
\end{array}\right)=\left(\begin{array}{cc}
\Delta_{\mathrm{jij}} & 0 \\
0 & \Delta_{r r}
\end{array}\right)\left(\begin{array}{cc}
\Delta_{\mathrm{j}} & 0 \\
0 & \Delta_{\mathrm{r}}
\end{array}\right)\left(\begin{array}{cc}
I & A_{j r} \Delta_{r} \\
A_{r j} \Delta_{j} & I
\end{array}\right)\left(\begin{array}{l}
Y_{j} \\
Y_{r}
\end{array}\right)
$$

Procedendo à multiplicação dos termos da expressão (13), tem-se

$$
\left(\begin{array}{l}
X_{j} \\
X_{r}
\end{array}\right)=\left(\begin{array}{cc}
\Delta_{i j} & 0 \\
0 & \Delta_{r r}
\end{array}\right)\left(\begin{array}{l}
A_{j} Y_{j}+\Delta_{j} A_{j r} \Delta_{r} Y_{r} \\
\Delta_{r} A_{r j} \Delta_{j} Y_{j}+\Delta_{r} Y_{r}
\end{array}\right)
$$

A partir da expressão (14), definem-se os índices puros de ligações para trás e para frente. Assim, o índice puro de ligações para trás pode ser definido como

$$
P B L=\Delta_{\mathrm{r}} \mathbf{A}_{\mathrm{rj}} \Delta_{\mathbf{j}} \mathbf{Y}_{\mathbf{j}}
$$

em que $P B L$ representa o impacto puro do valor da produção total do setor $j$ sobre a economia, não se considerando a demanda de insumos que o setor gera internamente, ou seja, dentro do próprio setor, bem como as demandas da economia como um todo para o setor $j$ e a demanda do setor $j$ para a economia como um todo.

Quanto ao índice puro de ligações para frente, é definido como $P F L=\triangle_{\mathrm{j}} \mathbf{A}_{\mathrm{jr}} \Delta_{\mathbf{r}} \mathbf{Y}_{\mathbf{r}}$

Já o $P F L$ indica o impacto puro sobre o setor $j$ provocado pela produção no resto da economia, ou seja, o restante da economia, para atender à sua demanda final, interage entre si, gerando uma demanda pelo setor $j$. O setor $j$ vai ter que produzir para atender a essa demanda.

Outra vantagem desses índices puros em relação ao de Hirschman-Rasmussen é que, caso se deseje saber qual é o índice puro do total de ligações (PTL) de cada setor na economia, é possível somar o $P B L$ com o $P F L$, dado que estes índices são expressos em valores correntes.

$$
P T L=P B L+P F L
$$

em que está representado o impacto puro da produção total no restante da economia no setor $j$.

Conforme especificado anteriormente, os índices puros de ligações são expressos em termos de valor da produção total. Assim, quando se pretende fazer uma análise comparativa, em diferentes períodos, desses índices e dos de ligações de Hirschman-Rasmussen, 
não é possível utilizar os índices puros de ligações. Para superar esse inconveniente, pode-se fazer uma normalização dos índices puros. Essa normalização é feita dividindo-se o valor da produção em cada setor pelo valor médio da economia.

O índice puro de ligação para trás normalizado é definido como

$$
P B L N=\frac{P B L}{\frac{\sum_{i}^{n} P B L}{n}}
$$

O índice puro de ligações para frente normalizado é

$$
P F L N=\frac{P F L}{\frac{\sum_{i}^{n} P F L}{n}}
$$

Já o índice puro total normalizado das ligações de cada setor será dado por:

$$
P T L N=\frac{P T L}{\frac{\sum_{i}^{n} P T L}{n}}
$$

De acordo com a eq. (20), pode-se perceber que, para obter o índice puro total de ligaçōes normalizado (PTLN) de cada setor da economia, não mais é possível somar o PBLN com o PFLN, visto que estes índices não são expressos em valores correntes.

\section{Resultados e discussão}

3.1 Análise das relações intersetoriais na economia brasileira e o segmento do turismo

As tabelas do modelo de insumo-produto construídas para o segmento do turismo no Brasil para o ano de 1999 são apresentadas no Anexo A1. A partir de então foi possivel estabelecer indicações sobre a participação dos diversos setores da economia no valor da produçāo e no valor adicionado, bem como analisar as relações intersetoriais na economia, conforme serão apresentadas e discutidas nesta subseção. 
Com o objetivo de dimensionar a participação dos setores na economia brasileira, com ênfase na participação do segmento do turismo, serão usados o valor adicionado e o valor da produção. Para esta análise, em vez de trabalhar com os 54 setores do modelo de insumo-produto para economia turística original, optou-se por fazer uma agregação destes em apenas seis macrossetores, a saber: Agropecuária, Indústria, Serviços industriais de utilidade pública, Construção civil, Serviços não-turísticos ${ }^{9}$ e Serviços turísticos. Este último foi desagregado nos seus doze setores originais, conforme mostrado na Tabela 1.

Ao analisar a Tabela 1 pode-se constatar que, dentre os macrossetores considerados, os Serviços não-turísticos foi o que apresentou a maior participação tanto no valor adicionado como no valor da produção, em que os setores que mais contribuíram para esta participação foram Administração pública, Aluguel de imóveis e Comércio. A segunda maior participação no valor adicionado e no valor da produção ficou para o macrossetor Indústria.

Tabela 1: Participação setorial no valor da produção e no valor adicionado, Brasil, 1999.

\begin{tabular}{|c|c|c|}
\hline Macrossetores & $\begin{array}{c}\text { Participação } \\
\text { setorial no valor } \\
\text { da produção (\%) }\end{array}$ & $\begin{array}{c}\text { Participação } \\
\text { setorial no valor } \\
\text { adicionado (\%) }\end{array}$ \\
\hline Agropecuária & 7,47 & 7,89 \\
\hline Indústria & 35,44 & 22,06 \\
\hline S.I.U.P. & 2,81 & 2,73 \\
\hline Construção civil & 8,37 & 9,06 \\
\hline Serviços não-turísticos & 41,70 & 54,68 \\
\hline Serviços turísticos & 4,22 & 3,59 \\
\hline Transporte rodoviário de passageiros, regular & 19,72 & 21,78 \\
\hline Transporte rodoviário de passageiros, náo-regular & 1,44 & 1,59 \\
\hline Transporte regular para expl. de ptos. turísticos & 0,02 & 0,02 \\
\hline Transporte aéreo, regular & 16,17 & 13,55 \\
\hline Transparte aéreo, náo-regular & 0,91 & 0,76 \\
\hline Agências e organizadores de viagens & 4,46 & 3,74 \\
\hline Atividades auxiliares aos transp. terrestre & 1,48 & 1,63 \\
\hline Atividades auxiliares aos transp. aéreos & 1,20 & 1,01 \\
\hline Estab. hoteleiros e outros tipos de aloj. temporário & 9,95 & 9,43 \\
\hline Restaurantes outros estab. de serv. de alimentação & 34,98 & 33,14 \\
\hline Atividades, recreativas, culturais e desportivas & 8,73 & 11,90 \\
\hline Aluguel de aut. outros meios de transporte & 0,95 & 1,46 \\
\hline
\end{tabular}

Fonte: Casimiro Filho (2002).

9 O macro-setor Serviços não-turísticos é composto pelos seguintes setores: Transporte rodoviário de cargas, Outros transportes terrestres, Transporte aquaviário, Ativ. auxiliares aos transportes aquaviários, Outras ativ. auxiliares ao transporte, Comércio, Comunicações, Instituições financeiras, Outros serviços prestados às familias, Outros serviços prestados às empresas, Aluguel de imóveis, Administração pública e Serviços privados nāo-mercantis. 
Sabe-se que o valor adicionado é dado pela diferença entre o valor bruto da produção e o consumo intermediário, ou seja, é o valor agregado pelos setores produtivos no decorrer do processamento da produção. Desse modo, pode-se inferir que os macrossetores acima referidos mostraram-se importantes impulsores da economia brasileira no período analisado.

Ainda com base na Tabela 1 e considerando apenas o macrossetor Serviços turísticos, pode-se perceber que o setor Restaurantes e outros estabelecimentos de serviços de alimentação apresenta uma maior participaçāo no valor adicionado e no valor da produção total, enquanto o que apresenta menor participação é o setor Transporte regular para exploração de pontos turísticos.

\subsubsection{Os índices Hirschman-Rasmussen}

Conforme apresentado anteriormente, a partir dos índices de ligações de Hirschman-Rasmussen, é possível identificar e analisar o grau de integração setorial de uma determinada economia, ou seja, a maneira como os setores econômicos se inter-relacionam tanto como demandantes de produtos de outros setores, como ofertantes de produtos a outros setores. No primeiro caso, tem-se o índice de ligação para trás e, no segundo caso, o índice de ligações para frente.

A análise dos índices de ligações para frente e para trás de Hirschman-Rasmussen é complementada pelos coeficientes de dispersão dos índices de ligações, à medida que estes possibilitam interpretar como um impacto setorial se distribui para os demais setores. A ocorrência de um valor baixo para uma dispersão do índice de ligação para trás significa que o impacto de uma variação na produção no setor tende a estimular os demais, de maneira uniforme, já um valor alto para este coeficiente significa que o impacto será concentrado em poucos setores. Para o caso do coeficiente de dispersão do índice de ligação para frente, um valor alto significa que a demanda por este setor está concentrada em poucos setores, enquanto que um baixo valor significa que este setor é demandado de maneira uniforme pelos demais da economia.

A Tabela 2 mostra os resultados dos índices de ligações de Hirschman-Rasmussen e os coeficientes de dispersão destes índices para os setores analisados, bem como a ordem de importância dos mesmos na economia. 
Tabela 2: Índices de ligações para trás e para frente de RasmussenHirschman e coeficiente de dispersão dos índices de ligações, Brasil, 1999.

\begin{tabular}{|c|c|c|c|c|c|c|c|c|c|}
\hline & Setores & $\begin{array}{c}\text { Ligaçōes } \\
\text { para } \\
\text { trás }\end{array}$ & Ordem & $\begin{array}{l}\text { Dispersão } \\
\text { para trás }\end{array}$ & Ordem & $\begin{array}{c}\text { Ligaçōes } \\
\text { para } \\
\text { frente }\end{array}$ & Ordem & $\begin{array}{c}\text { Dispersão } \\
\text { para } \\
\text { frente } \\
\end{array}$ & Ordem \\
\hline 1 & Agropecuária & 0,9056 & 40 & 5,1910 & 9 & 3,4300 & 2 & 1,9214 & 52 \\
\hline 2 & Extrativa mineral & 0,8279 & 46 & 4,9099 & 12 & 1,3217 & 10 & 3,0444 & 49 \\
\hline 3 & Mineral ñ metálico & 0,9982 & 30 & 4,6608 & 17 & 0,8776 & 19 & 5,2645 & 32 \\
\hline 4 & Siderurgia & 1,3008 & 1 & 5,0626 & 11 & 1,7334 & 4 & 3,8629 & 43 \\
\hline 5 & Metalurgia & 1,1885 & 8 & 4,2991 & 31 & 1,7056 & 5 & 2,9491 & 50 \\
\hline 6 & Máquinas e equip. & 0,9074 & 39 & 4,4875 & 21 & 1,0020 & 15 & 3,9861 & 42 \\
\hline 7 & Material elétrico & 1,1668 & 11 & 3,7324 & 50 & 0,6909 & 31 & 6,1079 & 25 \\
\hline 8 & Equip. eletrônicos & 0,9154 & 38 & 4,5807 & 20 & 0,6051 & 40 & 6,9354 & 12 \\
\hline 9 & Autom /cam/ônibus & 1,1066 & 17 & 3,6479 & 51 & 0,5616 & 47 & 7,0135 & 11 \\
\hline 10 & Peças e out. veículos & 1,1243 & 13 & 3,9953 & 39 & 1,2525 & 12 & 3,5599 & 45 \\
\hline 11 & Madeira e mobiliário & 1,0627 & 20 & 4,2025 & 34 & 0,6977 & 29 & 6,2672 & 22 \\
\hline 12 & $\begin{array}{l}\text { Celulose, papel } \\
\text { e grát. }\end{array}$ & 1,1092 & 15 & 4,6674 & 16 & 1,3610 & 9 & 3,7447 & 44 \\
\hline 13 & Ind da borracha & 1,0770 & 19 & 4,6330 & 18 & 1,1052 & 13 & 4,4010 & 38 \\
\hline 14 & Indústria química & 1,0079 & 27 & 5,2134 & 8 & 5,1681 & 1 & 1,0343 & 54 \\
\hline 15 & Farmac e veterinária & 0,9991 & 29 & 4,1814 & 35 & 0,6162 & 37 & 6,6727 & 16 \\
\hline 16 & Artigos plásticos & 1,0057 & 28 & 4,3854 & 25 & 0,9479 & 16 & 4,2996 & 40 \\
\hline 17 & Ind. têxtil & 1,2400 & 6 & 4,8186 & 13 & 1,4459 & 8 & 4,3648 & 39 \\
\hline 18 & Artigos do vestuário & 1,1699 & 10 & 3,8897 & 42 & 0,5399 & 51 & 7,2381 & 3 \\
\hline 19 & $\begin{array}{l}\text { Fabricação de } \\
\text { calçados }\end{array}$ & 1,0879 & 18 & 4,0794 & 37 & 0,6148 & 38 & 7,1451 & 6 \\
\hline 20 & Indústria do café & 1,2714 & 2 & 4,3367 & 27 & 0,6934 & 30 & 7,1035 & 8 \\
\hline 21 & Benef. prod vegetais & 1,1734 & 9 & 3,8807 & 43 & 0,7206 & 27 & 5,6041 & 28 \\
\hline 22 & Abate de animais & 1,2566 & 4 & 3,9384 & 40 & 0,6906 & 32 & 6,1269 & 24 \\
\hline 23 & Indústria de laticínios & 1,1612 & 12 & 4,2679 & 33 & 0,6598 & 34 & 7,0473 & 9 \\
\hline 24 & $\begin{array}{l}\text { Fabricação } \\
\text { de açúcar }\end{array}$ & 1,2525 & 5 & 3,8949 & 41 & 0,7194 & 28 & 6,4178 & 20 \\
\hline 25 & Fab. óleos vegetais & 1,2676 & 3 & 4,0939 & 36 & 0,8682 & 21 & 5,5819 & 29 \\
\hline 26 & $\begin{array}{l}\text { Oufros prod. } \\
\text { aliment. }\end{array}$ & 1,2019 & 7 & 3,5537 & 54 & 0,9197 & 18 & 4,5046 & 37 \\
\hline 27 & Indústrias diversas & 0,9940 & 31 & 4,0084 & 38 & 0,6580 & 35 & 5,9965 & 26 \\
\hline
\end{tabular}


Tabela 2: Índices de ligações para trás e para frente de RasmussenHirschman e coeficiente de dispersão dos índices de ligações, Brasil, 1999 (continuação)

\begin{tabular}{|c|c|c|c|c|c|c|c|c|c|}
\hline & Setores & $\begin{array}{l}\text { Ligaçōes } \\
\text { para trás }\end{array}$ & Ordem & $\begin{array}{l}\text { Dispersāo } \\
\text { para trás }\end{array}$ & Ordem & $\begin{array}{c}\text { Ligaçóes } \\
\text { para } \\
\text { frente }\end{array}$ & Ordem & $\begin{array}{l}\text { Dispersăo } \\
\text { para frente }\end{array}$ & Ordem \\
\hline 28 & S.I.U.P. & 0,9019 & 41 & 6,1804 & 3 & 1,5554 & 6 & 3,5321 & 47 \\
\hline 29 & Construção civil & 0,8821 & 44 & 4,6078 & 19 & 0,7241 & 26 & 5,5720 & 30 \\
\hline 30 & Comércio & 0,9312 & 32 & 4,4839 & 22 & 2,5431 & 3 & 1,5148 & 53 \\
\hline 31 & $\begin{array}{l}\text { Transp rodov de } \\
\text { passag, regular }\end{array}$ & 0,9240 & 35 & 4,3214 & 29 & 0,7519 & 24 & 5,1759 & 33 \\
\hline 32 & $\begin{array}{c}\text { Transp rodov passag., } \\
\text { nöo-regular }\end{array}$ & 0,9240 & 34 & 4,3002 & 30 & 0,5467 & 49 & 7,1300 & 7 \\
\hline 33 & $\begin{array}{l}\text { Transp. reg expl de pos } \\
\text { furísticos }\end{array}$ & 0,9240 & 36 & 4,2986 & 32 & 0,5307 & 53 & 7,3459 & 2 \\
\hline 34 & Transp rodov de cargas & 0,9240 & 33 & 4,3576 & 26 & 1,1017 & 14 & 3,5333 & 46 \\
\hline 35 & $\begin{array}{l}\text { Outr. transp. } \\
\text { terrestres }\end{array}$ & 1,1071 & 16 & 3,6115 & 53 & 0,5834 & 44 & 6,6776 & 15 \\
\hline 36 & Transp aquaviário & 0,8951 & 42 & 4,4201 & 23 & 0,5758 & 45 & 6,8599 & 13 \\
\hline 37 & Transp. aéreo, regular & 1,0582 & 23 & 3,8790 & 44 & 0,7837 & 23 & 5,1070 & 34 \\
\hline 38 & $\begin{array}{l}\text { Transp aéreo, não- } \\
\text { regular }\end{array}$ & 1,0586 & 22 & 3,7788 & 49 & 0,5447 & 50 & 7,1576 & 5 \\
\hline 39 & Agênc e org. de viagens & 1,0623 & 21 & 3,8084 & 48 & 0,7312 & 25 & 5,3454 & $31^{\circ}$ \\
\hline 40 & Ativ aux transp terrestre & 0,9214 & 37 & 4,3233 & 28 & 0,5860 & 43 & 6,6591 & 17 \\
\hline 41 & $\begin{array}{l}\text { Ativ aux transp. } \\
\text { aquaviários }\end{array}$ & 0,8901 & 43 & 4,4161 & 24 & 0,6116 & 39 & 6,4053 & 21 \\
\hline 42 & Ativ aux transp. aéreos & 1,0539 & 24 & 3,8086 & 47 & 0,5755 & 46 & 6,7886 & 14 \\
\hline 43 & Outr. ativ aux transporte & 1,1111 & 14 & 3,6259 & 52 & 0,6843 & 33 & 5,7324 & 27 \\
\hline 44 & Comunicações & 0,7436 & 52 & 5,3006 & 6 & 0,9478 & 17 & 4,1197 & 41 \\
\hline 45 & Instifuiçōes financeiras & 0,7646 & 48 & 5,5420 & 4 & 1,3146 & 11 & 3,1735 & 48 \\
\hline 46 & $\begin{array}{l}\text { Estab hotel e outr tipos } \\
\text { de aloj temporário }\end{array}$ & 1,0316 & 25 & 3,8294 & 46 & 0,5553 & 48 & 7,0181 & 10 \\
\hline 47 & $\begin{array}{c}\text { Rest. outr. estab de serv } \\
\text { de alimentação }\end{array}$ & 1,0316 & 26 & 3,8319 & 45 & 0,5894 & 42 & 6,6081 & 18 \\
\hline 48 & $\begin{array}{l}\text { Ativ recreativas, cult e } \\
\text { desportivas }\end{array}$ & 0,8324 & 45 & 4,6680 & 15 & 0,5939 & 41 & 6,5570 & 19 \\
\hline 49 & $\begin{array}{l}\text { Outr. serv prest. às } \\
\text { famílias }\end{array}$ & 0,8194 & 47 & 4,7873 & 14 & 0,6386 & 36 & 6,1465 & 23 \\
\hline 50 & $\begin{array}{l}\text { Aluguel autom. outr. } \\
\text { meios de transporte }\end{array}$ & 0,7577 & 50 & 5,1487 & 10 & 0,5392 & 52 & 7,2323 & 4 \\
\hline 51 & $\begin{array}{l}\text { Outr. serv. prest. às } \\
\text { empresas }\end{array}$ & 0,7577 & 49 & 5,4441 & 5 & 1,5485 & 7 & 2,6001 & 51 \\
\hline 52 & Aluguel de imóveis & 0,5656 & 54 & 6,8930 & 1 & 0,8356 & 22 & 4,6216 & 35 \\
\hline 53 & Administração pública & 0,7559 & 51 & 5,2297 & 7 & 0,8698 & 20 & 4,5745 & 36 \\
\hline 54 & Serv. priv. ñ mercantis & 0,5913 & 53 & 6,5804 & 2 & 0,5305 & 54 & 7,3485 & 1 \\
\hline
\end{tabular}

Fonte: Casimiro Filho (2002).

Analisando os índices de ligações para trás, observa-se que os setores apresentaram índices bastante heterogêneos, sendo que 28 setores estão mais integrados, indicando, assim, que a economia brasileira no ano de 1999 se encontrava relativamente interligada. Esse cenário pode ser resultado de mudanças econômicas adotadas durante os quatro primeiros anos do Plano Real e que proporcionaram ao Brasil um certo grau de dinamismo não verificado nos pri- 
meiros cinco anos da década de 1990, período em que, segundo Lima $\mathcal{E}$ Casimiro Filho (2000), a economia brasileira esteve pouco interligada. Essas mudanças modificaram os vínculos entre os fatores econômicos internos e externos e levaram ao incremento na entrada de investimentos diretos estrangeiros, ampliando, assim, o mercado interno brasileiro.

Especificamente, em relação aos investimentos no segmento do turismo, segundo Saab $\mathcal{E}$ Daemon (2001), houve nos últimos anos a entrada de cadeias internacionais de hotéis no país que, em conjunto com outros agentes econômicos, pretendem realizar investimentos significativos na construção e implantação de novas unidades hoteleiras no Brasil. Recentemente, também, instalaram-se aqui no Brasil alguns parques temáticos de propriedade de empresas estrangeiras, alguns já em operação e outros encontram-se em construção (Embratur/FADE, 1999).

Dentre os setores mais integrados, destacam-se, como de maior capacidade de interação com os setores vendedores, os seguintes: Siderurgia (4), Indústria de café (20), Fabricação de óleos vegetais (25), Abate de animais (22) e Fabricação de açúcar. Esses concentraram a demanda por insumos para o processo produtivo brasileiro.

Com relação aos setores que compõem o segmento do turismo, pode-se perceber que, embora não se encontrem entre os cinco principais demandantes, encontram-se entre os setores mais integrados na economia. Os setores vinculados ao turismo que apresentam esta característica são: Transporte aéreo, regular (37), Transporte aéreo, nāo-regular (38), Agências e organizadores de viagens (39), Atividades auxiliares ao transporte aéreo (42), Estabelecimentos hoteleiros e outros tipos de alojamento temporário (46) e Restaurantes e outros estabelecimentos de serviços de alimentação (47).

No que diz respeito aos índices de ligações para frente, ainda com base na Tabela 2, pode-se observar que a quantidade de setores que ofertam seus produtos como insumos para os demais setores do processo produtivo é menor que os setores os quais demandam, sendo formados por 14 outros (setores com índice superior a média). Considerando os cinco maiores índices de ligações para frente, observa-se que a oferta dos insumos se processou pelos seguintes setores: Indústria química (14), Agropecuária (1), Comércio (30), Siderurgia (4) e Metalurgia (5).

Analisando os setores que compõem o segmento do turismo, percebe-se que todos os setores apresentam índice de ligação para 
frente inferior à média, isto é, menor que a unidade. Essa informação evidencia que os produtos do segmento do turismo são pouco usados por outros setores no processo produtivo (consumo intermediário baixo), sendo destinados à demanda final, principalmente ao consumo das famílias e à exportação (consumo dos turistas estrangeiros no Brasil).

Com relação aos coeficientes de dispersão dos índices de ligação para trás, (Tabela 2) observa-se que os maiores coeficientes referem-se aos seguintes setores: Outros produtos alimentares (26), Outros transportes terrestres (35), Outras atividades auxiliares aos transportes (43), Peças e outros veículos (10) e Material elétrico (7). Desse modo, um impacto de uma variação de produção nesses setores estimularia os demais setores de maneira concentrada em poucos setores. Em relação ao segmento do turismo, observa-se que, na quase totalidade dos setores componentes, os coeficientes de variação dos índices são relativamente baixos, indicando que o segmento do turismo está bem articulado com os demais setores da economia brasileira. Assim, uma variação de produção nos setores que compōem tal segmento estimularia os demais, de maneira uniforme.

No que diz respeito aos coeficientes de dispersão dos índices de ligação para frente (Tabela 2), observa-se que os setores os quais compõem o segmento do turismo: Transporte regular para exploração de pontos turísticos (33), Aluguel de automóveis e outros meios de transporte (50), Transporte aéreo, regular (38), Transporte rodoviário, não-regular (32), apresentam valores relativamente altos de dispersão, significando que a demanda por estes setores ocorre de maneira concentrada. Esse resultado está ligado com a demanda final, conforme já foi explicado anteriormente. Já os setores que apresentaram baixos índices de dispersão foram: Indústria química (14), Comércio (30), Agropecuária (1), Outros serviços prestados às empresas (51) e Metalurgia (5), significando que a demanda por estes setores ocorre de maneira uniforme pelos demais setores da economia.

A partir dos índices de ligações para trás e para frente podemse classificar os setores como setores-chave dentro de um sistema econômico. McGilvray (1977) utiliza-se de um conceito mais restrito para definir um setor-chave. Segundo esse autor, um setor para ser considerado como um setor-chave dentro de uma economia deve apresentar os índices de ligações, tanto para frente como para trás, maiores que 1. Há, entretanto, alguns autores que utilizam um conceito mais abrangente para classificar um setor como sendo um se- 
tor-chave. Considerando esse conceito menos restrito, diz-se que um setor pode ser considerado como sendo um setor-chave, se o mes. mo apresentar um dos índices de ligação, para trás ou para frente, acima da média, isto é, maior do que 1 .

Os setores que podem ser classificados como sendo setoreschave na economia brasileira, para o ano aqui analisado, podem ser vistos na Figura 1.

De acordo com a referida figura e levando em consideração o conceito mais restrito, podem-se destacar sete setores-chave para o crescimento da economia brasileira: Siderurgia (4), Metalurgia (5), Peças e outros veículos (10), Celulose, papel e gráfica (12), Indústria da borracha (13), Indústria química (14) e Indústria têxtil (17). Conforme pode ser observado, todos esses setores pertencem à indústria de transformação. Esse resultado é o reflexo do processo de reestruturação pelo qual este setor vem passando desde o início da década de 1990, com resultados bastante positivos para alguns de seus segmentos. $O$ processo de reestruturação da indústria brasileira inclui um conjunto de reformas com o objetivo de dinamizar a economia brasileira, dentre as quais se podem destacar: reformas destinadas à liberalização do comércio; reformas destinadas à estabilização de preços, privatização de empresas; desregulamentação dos mercados de bens e serviços e eliminação de distorções nos sistemas tributários e financeiros.

\section{Figura 1: Setores-chave, Brasil, 1999}

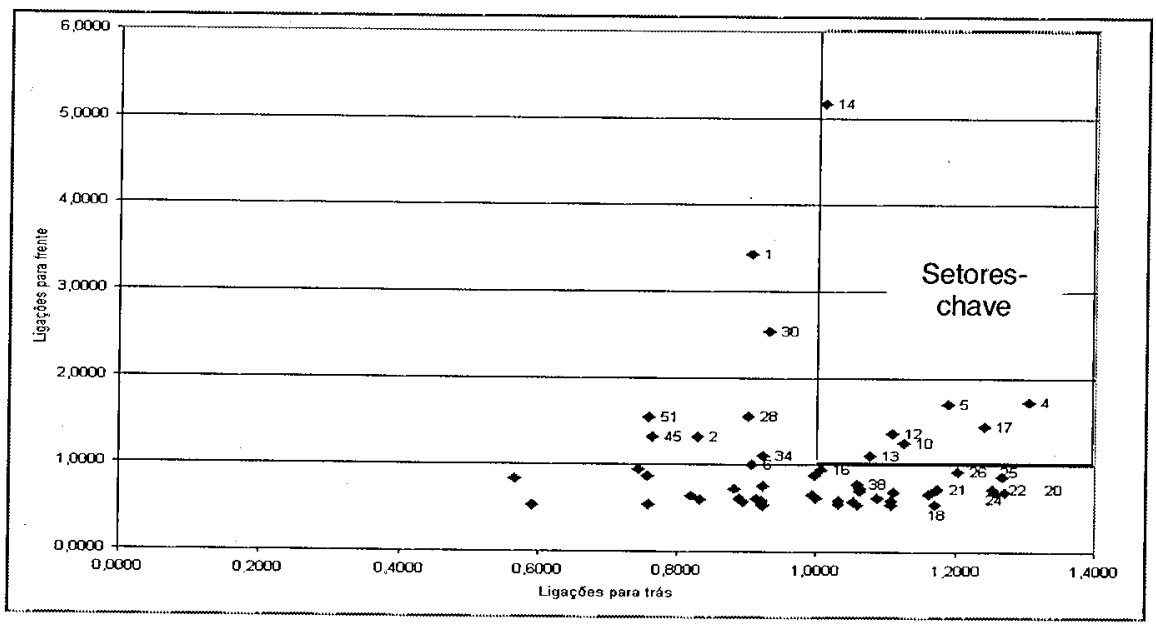


Aplicando o critério mais abrangente para classificar um setor como setor-chave, tem-se como resultado, além dos anteriormente citados, 29 setores-chave, (21 com ligações para trás e 8 com ligações para frente), sendo que, desses, 6 são componentes do segmento do turismo: Transporte aéreo, regular (37), Transporte aéreo, não-regular (38), Agência e organizadores de viagens (39), Atividades auxiliares ao transporte aéreo (42) Estabelecimentos hoteleiros e outros tipos de alojamento temporário (46), Restaurantes e outros estabelecimentos de serviços de alimentação (47). Esse conjunto de reformas para dinamizar a economia brasileira citado no parágrafo anterior, bem como a desvalorização cambial afetaram a estrutura produtiva do segmento do turismo. Verifica-se que ocorreu um avanço tecnológico com reflexos sobre os custos e preços finais dos produtos e serviços ofertados no mercado. Isso fez com que aumentasse o consumo do turismo interno pelos brasileiros e estrangeiros (Brasil, 2002a).

A definição de setores-chave indica os setores mais dinâmicos e, portanto, importantes para o crescimento da economia. Por isso, deveriam ser considerados prioritários, quando da implementação de investimentos. "Um crescimento dinâmico para o país só será possível com o fortalecimento dos complexos produtivos para os quais o país revele maior aptidão" (Brasil, 2002b, p. 13).

\subsubsection{Campo de influência}

Com o objetivo de complementar a análise dos índices de Hirschman-Rasmussen e identificar como se distribuem as alterações dos coeficientes diretos de produção no sistema econômico como um todo, ou seja, identificar os elos da economia, foi calculado o campo de influência.

Assim, as relações intersetoriais mais importantes dentro do processo produtivo da economia brasileira para o ano de 1999 podem ser vistas na Figura 2. Vale ressaltar que foram considerados os 200 coeficientes com maior campo de influência, plotados nos 54 setores aqui estudados. Pode-se perceber que, se ocorressem pequenas alterações nos coeficientes diretos de produção, o setor Siderurgia (4) seria o grande propagador dessas alteraçōes no sistema econômico, visto que o mesmo apresentou 19 coeficientes relativos à venda e 33 coeficientes envolvendo compras. O segundo maior propagador das alterações nos coeficientes diretos de produção no 
sistema econômico seria o setor Indústria têxtil (17) com 10 coeficientes envolvendo vendas e 22 envolvendo compras.

Figura 2: Coeficientes setoriais com maior campo de influência, Brasil, 1999.

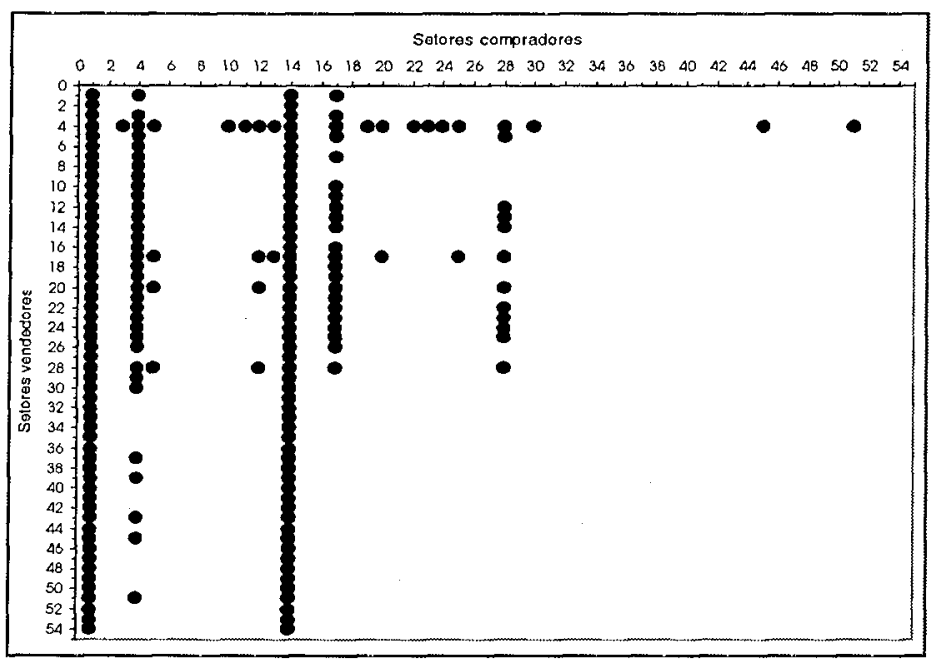

Considerando somente o lado das compras, ou seja, analisando a importância dos setores como compradores de insumos dos demais setores da economia, podem-se ressaltar: Agropecuária (1) e Industria química (14) comprando de todos os setores do sistema econômico. Este resultado confirma a opinião de alguns analistas econômicos de que a agricultura brasileira está alcançando um avanço tecnológico. Segundo Brasil (2002), em estudo sobre os seis anos do Plano Real, um indicador expressivo deste avanço é a evolução do consumo de fertilizantes de 11,2 milhōes de toneladas em 1994 para 14,3 milhões em 1999. Seguindo esta mesma trajetória, o consumo de nutrientes e matéria-prima, por parte deste setor, também tem apresentado crescimento constante.

\subsubsection{Os índices puros de ligações}

Nos cálculos e análises do índice de Hirschman-Rasmussen não se leva em consideração o valor da produção dos setores para medir a importância econômica destes, o que, segundo Guilhoto et al. (1996), é feito pelos índices puros. Assim, alguns comentários merecem ser feitos antes de se analisarem os índices puros de ligação, os 
quais apresentam a vantagem, em relação aos índices de HirschmanRasmussen, de classificar os setores-chave, considerando, não apenas as suas ligações com outros setores, como também o valor de sua produção total. Por essa razão podem-se eleger setores-chave diferentes dos que foram eleitos anteriormente, quando foi considerado o índice de ligação de Hirschman-Rasmussen.

$\mathrm{Na}$ Tabela 3 são apresentados os resultados referentes aos índices puros de ligaçōes intersetoriais para trás, para frente e total, ambos normalizados conforme definido no capítulo anterior, de modo a facilitar a análise. É apresentada, também, a ordem de importância dos 54 setores na economia de acordo com o índice puro. A análise desses índices tem como objetivo medir a importância de um dado setor para o resto da economia em termos de seu valor da produção.

Tabela 3: Índices puros de ligaçōes normalizados para trás, para frente e total, Brasil, 1999.

\begin{tabular}{|c|c|c|c|c|c|c|c|}
\hline & Setores & $\begin{array}{l}\text { Ligaçōes } \\
\text { para trás }\end{array}$ & Ordem & $\begin{array}{c}\text { Ligaçōes } \\
\text { para } \\
\text { frente }\end{array}$ & Ordem & $\begin{array}{c}\text { Ligaçōes } \\
\text { totais }\end{array}$ & Ordem \\
\hline 1 & Agropecuária & 2,1370 & 8 & 6,2046 & 2 & 4,1620 & 3 \\
\hline 2 & Extrativa mineral & 0,2577 & 37 & 1,5929 & 10 & 0,9224 & 20 \\
\hline 3 & Mineral ñ metálico & 0,1485 & 40 & 1,7000 & 9 & 0,9209 & 21 \\
\hline 4 & Siderurgia & 0,3791 & 36 & 2,0038 & 7 & 1,1879 & 14 \\
\hline 5 & Metalurgia & 0,6910 & 21 & 2,8017 & 5 & 1,7418 & 8 \\
\hline 6 & Máquinas e equip. & 1,0605 & 12 & 0,9695 & 16 & 1,0152 & 17 \\
\hline 7 & Material elétrico & 0,9645 & 15 & 0,4867 & 26 & 0,7266 & 27 \\
\hline 8 & Equip. eletrônicos & 0,5400 & 27 & 0,0849 & 42 & 0,3135 & 39 \\
\hline 9 & Autom /cam/ônibus & 1,8958 & 10 & 0,0598 & 46 & 0,9817 & 18 \\
\hline 10 & Peças e out veículos & 0,8619 & 17 & 1,0516 & 14 & 0,9563 & 19 \\
\hline 11 & Madeira e mobiliário & 0,7715 & 19 & 0,4552 & 28 & 0,6140 & 29 \\
\hline 12 & Celulose, papel e gráf. & 0,4844 & 29 & 1,7671 & 8 & 1,1230 & 15 \\
\hline 13 & Ind da borracha & 0,0994 & 44 & 0,7643 & 20 & 0,4304 & 35 \\
\hline 14 & Indústria química & 0,5421 & 26 & 8,9589 & 1 & 4,7323 & 1 \\
\hline 15 & Farmac e veferinária & 1,0433 & 13 & 0,2475 & 34 & 0,6471 & 28 \\
\hline 16 & Artigos plásticos & 0,0954 & 45 & 0,8955 & 19 & 0,4937 & 33 \\
\hline 17 & Ind têxtil & 0,4331 & 33 & 1,1741 & 13 & 0,7722 & 24 \\
\hline 18 & Artigos do vestuário & 1,0174 & 14 & 0,0192 & 51 & 0,5205 & 31 \\
\hline 19 & Fabricação calçados & 0,4379 & 32 & 0,0361 & 48 & 0,2379 & 42 \\
\hline 20 & Indústria do café & 0,8541 & 18 & 0,0673 & 44 & 0,4624 & 34 \\
\hline 21 & Benef. prod vegetais & 2,1844 & 7 & 0,5648 & 25 & 1,3781 & 11 \\
\hline 22 & Abate de animais & 2,4354 & 5 & 0,2655 & 33 & $\cdot 1,3551$ & 12 \\
\hline 23 & Indústria de laticínios & 0,5956 & 25 & 0,1166 & 40 & 0,3571 & 38 \\
\hline 24 & Fabricaçāo de açúcar & 0,5183 & 28 & 0,2460 & 35 & 0,3827 & 36 \\
\hline 25 & Fab. óleos vegetais & 0,8898 & 16 & 0,6225 & 23 & 0,7567 & 25 \\
\hline 26 & Outros prod aliment & 2,6059 & 4 & 0,9443 & 18 & 1,7787 & 7 \\
\hline 27 & Indústrias diversas & 0,3971 & 35 & 0,3671 & 30 & 0,3821 & 37 \\
\hline
\end{tabular}


Tabela 3: Índices puros de ligações normalizados para trás, para frente e total, Brasil, 1999 (continuação).

\begin{tabular}{|c|c|c|c|c|c|c|c|}
\hline & Setores & $\begin{array}{l}\text { Ligaçōes } \\
\text { para trás }\end{array}$ & Ordem & $\begin{array}{c}\text { Ligaçōes } \\
\text { para } \\
\text { frente }\end{array}$ & Ordem & $\begin{array}{c}\text { Ligaçōes } \\
\text { totais }\end{array}$ & Ordem \\
\hline 28 & S.I.U.P. & 0,4019 & 34 & 2,1340 & 6 & 1,2642 & 13 \\
\hline 29 & Construçāo Civil & 7,1990 & 1 & 0,7465 & 22 & 3,9867 & 4 \\
\hline 30 & Comércio & 4,6027 & 3 & 4,5987 & 3 & 4,6007 & 2 \\
\hline 31 & $\begin{array}{l}\text { Transp. rodov. de passag., } \\
\text { regular }\end{array}$ & 0,5979 & 24 & 0,4566 & 27 & 0,5275 & 30 \\
\hline 32 & $\begin{array}{l}\text { Transp. rodov, passag., não- } \\
\text { regular }\end{array}$ & 0,0441 & 48 & 0,0337 & 49 & 0,0389 & 50 \\
\hline 33 & $\begin{array}{l}\text { Transp. reg. expl. de ptos. } \\
\text { turísticos }\end{array}$ & 0,0005 & 54 & 0,0004 & 53 & 0,0005 & 54 \\
\hline 34 & Transp. rodov. de cargas & 0,6070 & 23 & 1,1625 & 12 & 0,8835 & 22 \\
\hline 35 & Outr. transp terrestres & 0,2085 & 38 & 0,1337 & 39 & 0,1712 & 43 \\
\hline 36 & Transp. aquaviário & 0,0823 & 46 & 0,0700 & 43 & 0,0761 & 46 \\
\hline 37 & Transp. aéreo, regular & 0,6789 & 22 & 0,3162 & 32 & 0,4983 & 32 \\
\hline 38 & Transp. aéreo, não-regular & 0,0394 & 49 & 0,0189 & 52 & 0,0292 & 52 \\
\hline 39 & Agência e org de viagens & 0,0544 & 47 & 0,2330 & 36 & 0,1433 & 44 \\
\hline 40 & Ativ. aux. transp. terrestre & 0,0256 & 52 & 0,0609 & 45 & 0,0432 & 49 \\
\hline 41 & Ativ. aux transp aquaviários & 0,0341 & 50 & 0,0888 & 41 & 0,0613 & 47 \\
\hline 42 & Ativ. aux, transp. aéreos & 0,0278 & 51 & 0,0494 & 47 & 0,0385 & 51 \\
\hline 43 & Outr. ativ. aux. transporte & 0,1046 & 43 & 0,1679 & 37 & 0,1361 & 45 \\
\hline 44 & Comunicaçōes & 0,4638 & 31 & 1,0466 & 15 & 0,7540 & 26 \\
\hline 45 & Instituiçōes financeiras & 1,9125 & 9 & 1,5035 & 11 & 1,7089 & 9 \\
\hline 46 & $\begin{array}{c}\text { Estab: hotel. e outr. tipos de } \\
\text { aloj. temporário }\end{array}$ & 0,4694 & 30 & 0,1457 & 38 & 0,3082 & 40 \\
\hline 47 & $\begin{array}{c}\text { Estab. outr. estab. de serv. de } \\
\text { alimentação }\end{array}$ & 1,8041 & 11 & 0,3439 & 31 & 1,0772 & 16 \\
\hline 48 & $\begin{array}{l}\text { Ativ. recreativas, } \\
\text { cult. e desportivas }\end{array}$ & 0,1074 & 42 & 0,3768 & 29 & 0,2415 & 41 \\
\hline 49 & Outr. serv prest às familias & 2,3463 & 6 & 0,5754 & 24 & 1,4647 & 10 \\
\hline 50 & $\begin{array}{l}\text { Aluguel autom. outr. } \\
\text { meios de fransporte }\end{array}$ & 0,0130 & 53 & 0,0310 & 50 & 0,0220 & 53 \\
\hline 51 & $\begin{array}{l}\text { Outr. serv. prest. } \\
\text { às empresas }\end{array}$ & 0,1843 & 39 & 3,6024 & 4 & 1,8859 & 6 \\
\hline 52 & Aluguel de imóveis & 0,7039 & 20 & 0,9456 & 17 & 0,8242 & 23 \\
\hline 53 & Administração pública & 6,8350 & 2 & 0,7504 & 21 & 3,8058 & 5 \\
\hline 54 & Serv priv $\bar{n}$ mercantis & 0,1109 & 41 & 0,0000 & 54 & 0,0557 & 48 \\
\hline
\end{tabular}

Fonte: Casimiro Filho (2002).

Sabe-se que o índice puro de ligação para trás mostra o impacto puro do valor da produção total de um determinado setor sobre o restante da economia. Enquanto o índice puro de ligação para 
frente mostra o impacto puro da produção total do resto da economia nos setores.

Considerando o índice puro de ligação para trás normalizado, pode-se perceber que os cinco maiores demandantes foram os setores: Construção civil (29), Administração pública (53), Comércio (30), Outros produtos alimentares (26) e Abate de animais (22). Dessa forma, pode-se inferir que, considerando o valor da produção, estes setores foram os que mais impactaram a economia no ano aqui analisado, já os setores que menos provocaram impacto na economia, ou seja, que apresentaram os menores índices puros de ligação para trás normalizados, no ano de 1999, foram: Transporte regular para exploração de pontos turísticos (33), Aluguel de automóveis e outros meios de transportes (51), Atividades auxiliares aos transportes terrestres (40), Atividades auxiliares aos transportes aéreos (42), e Atividades auxiliares aos transportes aquaviários (50).

Analisando os índices puros de ligação para frente normalizados, observa-se que os cinco maiores ofertantes de insumos, ou mais demandados na economia foram: Indústria química (14), Agropecuária (1), Comércio (30), Outros serviços prestados às empresas (51) e Metalurgia (5). Esses são os setores nos quais a produção total do resto da economia gera mais impacto puro, já os menos demandados, o que, por conseqüência, a produção total do resto da economia gera menos impacto puro, foram: Transporte regular para exploração de pontos turísticos (33), Transporte aéreo, regular (38), Artigos de vestuário (18), Aluguel de automóveis e outros meios de transportes (50) e transportes de passageiros, não-regular (32).

Constatou-se, analisando a Tabela 3, que os setores os quais compõem o segmento do turismo apresentaram valores desses índices, de modo geral, baixos, com exceção do setor restaurante e outros estabelecimentos de serviços de alimentação (47). Esse resultado mostra que tanto o impacto puro do valor da produção total dos setores em destaque na economia, evidenciado pelo índice puro de ligação para trás, como o impacto puro da produção total do restante da economia sobre os setores do segmento do turismo foram relativamente baixos.

Para eleger os setores-chave de uma economia, levando-se em consideração os índices puros de ligação normalizados, o critério a ser adotado é o que segue: serão considerados setores-chave aqueles cujos índices puros de ligações totais normalizados forem maior que a unidade. De acordo com esse critério, examinando a Tabela 
3, tem-se os seguintes setores-chave: Indústria química (14), Comércio (30), Agropecuária (1), Construção civil (29), Administração pública (53), Outros serviços prestados às empresas (51), Outros produtos alimentares (26), Metalurgia (5), Instituições financeiras (45), Outros serviços prestados às famílias (49), Beneficiamentos de produtos vegetais (21), Abate de animais (22), Serviços industriais de utilidade pública (28), Siderurgia (4), Celulose, papel e gráfica (12), Restaurantes e outros estabelecimentos de serviços de alimentação (47) e Máquinas e equipamentos (6).

Como pode ser observado, os setores-chave da economia brasileira no ano de 1999 apresentaram uma grande diversidade. Isso pode ser atribuído à heterogeneidade da estrutura econômica do país e à forma positiva com que os diferentes segmentos vêm reagindo às mudanças econômicas introduzidas desde a implantação do real. $\mathrm{O}$ grande número de setores-chave reflete uma economia dinâmica, que está retomando gradativamente o crescimento, graças ao aporte de investimentos diretos estrangeiros, ao aumento das exportações - principalmente manufaturados, ao aperfeiçoamento dos mecanismos de controle de importações, à desvalorização cambial e à adoção de novas tecnologias.

Conforme já mencionado anteriormente, a abordagem dos índices puros de ligação aponta a importância dos setores econômicos, considerando, além das ligações intersetoriais, o seu volume de produção. Dessa forma, esses índices não conseguem captar a importância econômica dos setores com baixos volumes de produção, o que é possível, através dos índices de ligação de HirschmanRasmussen, daí o surgimento de divergências na eleição dos setores relevantes da economia. Assim, torna-se necessária uma comparação dos dois índices, para que se chegue a uma identificação correta dos setores-chave.

Comparando-se os índices puros de ligação normalizados e os índices de ligação de Hirschman-Rasmussen, observa-se um número maior de setores-chave quando são considerados os índices de ligação de Hirschman-Rasmussen (critério de escolha menos restrito). Pelo exposto, no entanto, até aqui se observa que existe alguma similaridade nos resultados dos setores relevantes, quando se analisam os índices de Hirschman-Rasmussen e os índices puros de ligação. As principais divergências, entretanto, ocorreram nos setores que fazem parte do segmento do turismo, tendo em vista os baixos volumes de produção destes setores. 
Cabe aqui ressaltar que os resultados encontrados estão associados ao nível de agregação adotado. Sendo assim, algumas divergências que foram encontradas na análise dos setores-chave poderiam ser sanadas, caso fosse adotado um outro nível de agregação.

\section{Considerações finais}

Esta pesquisa teve como objetivos a construção de um modelo de insumo-produto para a economia turística no Brasil, no ano de 1999 e, a partir deste modelo, mensurar e analisar as relações intersetoriais, bem como a capacidade de indução dos investimentos sobre o crescimento da economia. Objetivou-se, também, delinear uma metodologia de mensuração do produto interno bruto do segmento do turismo através do modelo de insumo-produto.

A mensuração e análise dos índices de ligações intersetoriais permitiram a identificação dos setores-chave, considerando o modelo de insumo-produto aqui construído e o nível de agregação utilizado. Dentre os setores que foram classificados como setores-chave, são seis os que foram inicialmente considerados como componentes do segmento do turismo: Transporte aéreo, regular, Transporte aéreo, não regular, Agências e organizadores de viagens, Atividades auxiliares aos transportes aéreos, Estabelecimentos hoteleiros e outros tipos de alojamento temporário, e Restaurantes e outros estabelecimentos de serviços de alimentação.

Obviamente, a presente pesquisa apresenta limitações e, portanto, seus resultados devem ser vistos como indicações do comportamento do segmento do turismo na economia brasileira. Estas limitações, porém, não invalidam o estudo; ao contrário, cria-se um conjunto de informaçōes importantes para orientar o poder público na definição e adoção de políticas específicas para o os setores que compõem o segmento do turismo e o setor privado no direcionamento de seus investimentos.

Como sugestão para trabalhos futuros que possam complementar e/ou aprofundar o presente estudo, pode-se destacar: a) construir e atualizar matrizes para a economia turística a preços constantes de um dado ano-base, permitindo, assim, a separação entre as mudanças ocorridas nos preços relativos e as provenientes de inovação tecnológica; b) construir um modelo de insumo-produto inter-regional para a economia turística e, com isso, mensurar a importância 
econômica do segmento do turismo nas macrorregiōes brasileiras; c) desagregar os setores componentes da demanda final, principalmente o consumo das famílias, para que se possa separar o consumo turístico do consumo não-turístico.

Por último, sugere-se aos órgãos públicos e privados a forma* ção de banco de dados que permita, com maior precisão, construir os modelos de insumo-produto para o segmento do turismo no Brasil e regiões.

\section{Referências bibliográficas}

BRASIL. Secretaria de Comunicação de Governo. 6 anos do Real: crescimento e desenvolvimento social. http://www.planalto.gov.br (06/03/2002).

BRASIL, H.S. Análise econômica do turismo no Brasil. http://www.embratur.gov.br/ economia (21/01/2002a).

BRASIL. Ministério da Indústria, Comércio e Turismo; Secretaria de Política Industrial. Ações setoriais para o aumento da competitividade da indüstria brasileira. http://www.midc.gov.br/publica/ (06/03/2002b).

BRIASSOULIS, H. "Methodological issues: tourism input-output analysis". Annals of Tourism Research, v.18, n.3, p.485-495, 1991.

BULMER-THOMAS, V. Input-output analysis in developing countries: source, methods and applications. New York: Wiley, 1992.297p.

CASIMIRO FILHO, F. Contribuições do turismo à economia brasileira. Piracicaba, 2002. 220p. Tese (Doutorado) - Escola Superior de Agricultura Luiz de Queiroz, Universidade de São Paulo.

CRUZ, R. C. Politica de turismo e território. São Paulo: Contexto, 2000. 167p.

ESPANHA. Ministerio de Comercio y Turismo. Instituto de Estudios Turísticos. Tabla intersectorial de la economía turística: TIOT-92. Madri: Instituto de Estudios Turísticos, 1996.351p. (Série Informe sobre turismo, 6)

GUILHOTO, J.J.M.; SONIS, M.; HEWINGS, G.J.D. Linkages and multipliers in a multiregional framework: integration of alternative approaches. Urbana: University of Illinois/Regional Economics Applications Laboratory, 1996. (Discussion paper) GUILHOTO, J.J.M.; SONIS, M.; HEWINGS, G.J.D.; MARTINS, E.B. "Índices de ligações e setores-chave na economia brasileira: 1959-1980". Pesquisa e Planejamento Econômico, v.24, n.2, p.287-314, ago. 1994.

GUILHOTO, J.J.M.; OLIVEIRA, A.F.; GRAMEIRO, A. H. et al. Notas metodológicas de construção da matriz de insumo-produto para economia brasileira para 1999. Piracicaba: DEAS/ESALQ/USP, 2001. (Relatório de atividades) 
INSTITUTO BRASILEIRO DE GEOGRAFIA E ESTATÍSTICA. Matriz de relações intersetoriais: Brasil - 1980. Rio de Janeiro: IBGE, 1989. 203p.

INSTITUTO BRASILEIRO DE GEOGRAFIA E ESTATÍSTICA. Estrutura produtiva da economia brasileira: censo cadastro 1995: Rio de Janeiro: IBGE, 1997. 142p.

INSTITUTO BRASILEIRO DE GEOGRAFIA E ESTATÍSTICA. Sistema de contas nacionais: Brasil, 1990-1995. Rio de Janeiro: IBGE, 1997a. 298p.

INSTITUTO BRASILEIRO DE TURISMO; FUNDAÇÃO DE APOIO AO DESENVOLVIMENTO DA UFPE. Estudo econômico-financeiro dos meios de hospedagense parque temáticos no Brasil. Brasilia: EMBRATUR, 1998. 180p.

INSTITUTO BRASILEIRO DE TURISMO; FUNDAÇĂO DE APOIO AO DESENVOLVIMENTO DA UFPE. "Estudo econômico-financeiro dos meios de hospedagens e parque temáticos no Brasil". In: INSTITUTO BRASILEIRO DE TURISMO. Estudos do turismo brasileiro. Brasilia: EMBRATUR, 1999. cap. 4, p.181-220.

LAGE, B.H.G; MLLONE, P.C. Economia do turismo. Campinas: Papirus, 1991. 122p. LIMA, P.V.P.S.; CASIMIRO FILHO, F. "Análise da estrutura produtiva da agropecuária brasileira no período de 1993 e 1995". (compact disc) In: CONGRESSO BRASILEIRO DEECONOMIA ESOCIOLOGIARURAL, 38., Rio de Janeiro, 2000. Anais. Brasilia: SOBER, 2000.

LOPES, J.C. "O turismo e o desenvolvimento regional do Norte e Nordeste". Informações FIPE, n.120, p.15-17, jul. 1990.

LUNDEBERG, D.E.; KRISHNAMOORTHY,M.; STAVENGA, M.H. Tourismeconomics. New York: John Wiley ES Sons, 1995. 196p.

McGILVRAY, J. "Linkages, key sectors and development strategy". In: Leontief, W. (Ed.). Structure, system and economic policy. Cambridge: University Press, 1977. p.49-56.

MILLER, R.E.; BLAIR, P.D. Input-output analysis: foundations and extensions. Englewood Ciffs: Prentice-Hall, 1985. 464p.

PACI, E. "El papel del turismo en el sistema económico". In: ESPANHA. Ministerio de Comercio y Turismo. Instituto de Estudios Turísticos. Tabla intersectorial de la economía turística: TIOT-92. Madri: Instituto de Estudios Turísticos, 1996. p.154211. (Série Informe sobre turismo, 6).

SAAB, W.G.L. "Consideraçōes sobre o desenvolvimento do setor de turismo no Brasil". BNDES Setorial, n.10, p. 285-312, set. 1999.

SAAB, W.G.L.; DAEMON, I.G. "O segmento hoteleiro no Brasil". BNDES Setorial, n.13, p.127-156, mar. 2001.

SONIS, M.; HEWINGS, G.J.D. "Erro and sensitivity input-output analysis: a new approach". In: MILLER, R.E.; POLENSKE, K.R.; ROSE, A.Z. (Ed.). Frontiers of inputoutput analysis. New York: Oxford University Press, 1989. p. 232-244. 
SONIS, M.; HEWINGS, G.J.D. Fieds of influence in input-output systems. Urbana: University of Illinois/Regional Economics Applications Laboratory, 1995. 27p. WORLD BANK. Growth of output. http:/www.worldbank org/data (02/04/2001). WORLD TOURISM ORGANIZATION. Tourism highlights. http://www.worldtourism.org $(12 / 11 / 2000)$. 
Tabela A1: Matriz de insumo-produto agregada nos setores para economia turística, Brasil, 1999 (valores correntes em 1.000 R\$)

\begin{tabular}{|c|c|c|c|c|c|c|c|c|c|c|c|c|c|c|c|c|c|c|c|c|c|c|c|c|c|c|}
\hline 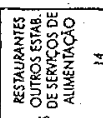 & $=$ & 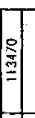 & శ్ & s. & $1-$ & 总 & $\approx$ & 兽 & $\cong$ & $\tilde{\Xi}$ & $\stackrel{\stackrel{\circ}{g}}{\underline{y}}$ & $\frac{2}{0}$ & $\begin{array}{l}\frac{2}{2} \\
0 \\
\end{array}$ & $\grave{\Phi}$ & $\mid$ & 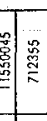 & 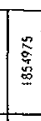 & 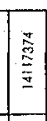 & 总 & 总 & \begin{tabular}{|l}
$\frac{2}{0}$ \\
$\frac{\alpha}{\bar{g}}$ \\
$\underline{8}$
\end{tabular} & 吣 & 0 & 唁 & 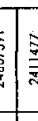 & \\
\hline 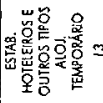 & & & กิ & T & $1-$ & 总 & $\approx$ & 空 & 要 & $\because$ & $\mp$ & $\stackrel{\varrho}{=}$ & $\%$ & $\vec{\Xi}$ & 总: & 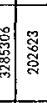 & $\overline{\overline{3}}$ & $\mid \begin{array}{l}\text { 总 } \\
\text { 索 }\end{array}$ & 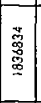 & 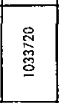 & 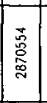 & 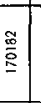 & - & 恿 & 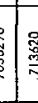 & \\
\hline 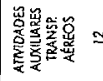 & & & 萝 & $\bar{\Xi}$ & $\underline{m}$ & 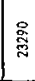 & 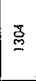 & 㐁 & 荬 & 记 & बे & $\Xi$ & : & $\stackrel{\frac{\infty}{N}}{\pi}$ & 产 & 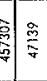 & 趌 & 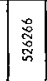 & 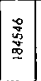 & 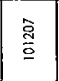 & 总 & 豆 & 总 & 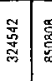 & : & \\
\hline 5 & & & $\overrightarrow{\underline{\underline{\theta}}}$ & $\&$ & $\sigma$ & \begin{tabular}{|l|}
$\overline{\mathbf{g}}$ \\
$\underline{\underline{G}}$
\end{tabular} & $\frac{1}{\alpha}$ & 罗 & $\mid \frac{\alpha}{\alpha}$ & $\frac{\tilde{2}}{2}$ & $\stackrel{\infty}{7}$ & $\approx$ & $\frac{ \pm}{\Xi}$ & $\bar{\Phi}$ & 羉 & 竘) & 螪 & 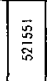 & 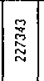 & 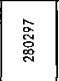 & 患 & 흘 & 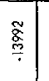 & 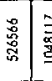 & 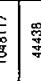 & \\
\hline 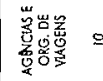 & & & : & $\vec{\Delta}$ & $\infty$ & 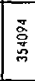 & 产 & $\therefore$ & $\underline{\infty}$ & $\simeq$ & 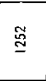 & 总 & 焉 & $\overline{\bar{\infty}}$ & $\mid \frac{\overline{0}}{2}$ & 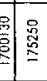 & 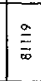 & $\mid \begin{array}{l}\text { 稿 } \\
\text { 尊 }\end{array}$ & 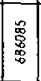 & 总 & 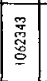 & $\widetilde{\widetilde{m}}$ & ฐุ & & 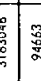 & \\
\hline 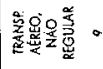 & & & & $\ddot{\bar{N}}$ & $\curvearrowright$ & 管 & $\approx$ & 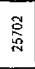 & 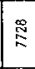 & 戀 & 晃 & $\stackrel{\circ}{\circ}$ & 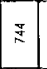 & $\stackrel{20}{2}$ & \begin{tabular}{|l|l}
\multirow{2}{*}{} \\
$=$ \\
$=$
\end{tabular} & 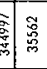 & $\begin{array}{l}\bar{y} \\
\underline{0}\end{array}$ & \begin{tabular}{|l|}
$\overline{\tilde{s}}$ \\
总 \\
\end{tabular} & $\mid \begin{array}{c}\tilde{s} \\
\tilde{g}\end{array}$ & 落 & 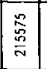 & 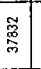 & 商 & & \begin{tabular}{|l|l}
0 \\
8 \\
\end{tabular} & \\
\hline & & & & 営 & $\equiv$ & 总 & 总 & 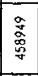 & $\stackrel{\circ}{2}$ & 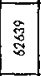 & 旓 & 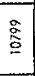 & 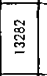 & 栚 & 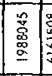 & 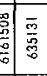 & 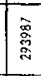 & \begin{tabular}{|c|}
\multirow{3}{*}{} \\
豙 \\
\end{tabular} & 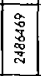 & 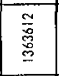 & 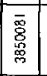 & 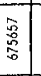 & 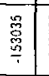 & & 商 & \\
\hline 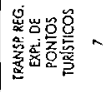 & & & & $\sim$ & 0 & + & 0 & $\stackrel{\sim}{.}$ & $\bar{\varnothing}$ & $\because$ & $n$ & $=$ & $=$ & $\cdots$ & $\underline{\underline{Q}}$ & ज़ & $\%$ & 总 & $\bar{\sim}$ & 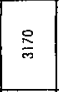 & $\bar{\Sigma}$ & 跑 & $\stackrel{\infty}{7}$ & 憙 & 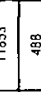 & \\
\hline 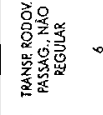 & & & & $\overline{\underline{\alpha}}$ & $a$ & $\stackrel{2}{5}$ & $\bar{\sim}$ & $\frac{2}{\pi}$ & 胥 & 5 & \% & $\bar{\alpha}$ & $\stackrel{\mathscr{m}}{=}$ & $\hat{\underline{\Omega}}$ & 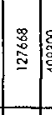 & 8 & ঙู้ & 爰 & $\mid \frac{\vec{z}}{\stackrel{2}{*}}$ & $\begin{array}{l}\text { mo } \\
\text { స్ }\end{array}$ &  & 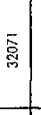 & 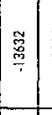 & $\begin{array}{l}\frac{8}{2} \\
\frac{2}{\omega}\end{array}$ & $\begin{array}{l}8 \\
\end{array}$ & \\
\hline 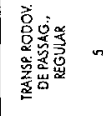 & & & $\tilde{\widetilde{\tilde{\Xi}}}$ & 总 & $\circ$ & $\frac{\mathscr{8}}{\circ}$ & $\mathbb{\approx}$ & $\mid \begin{array}{l}0 \\
0 \\
0 \\
\end{array}$ & $\frac{a}{y_{0}^{2}}$ & 愛 & 芯 & $\frac{\hat{o}}{2}$ & 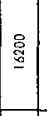 & $\frac{O}{N}$ & 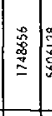 & 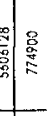 & 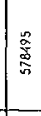 & 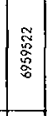 & 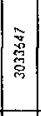 & 离 & 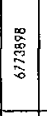 & 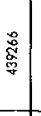 & 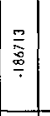 & 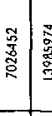 & 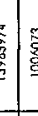 & \\
\hline 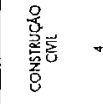 & & 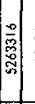 & 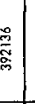 & 范 & व्ल & 总 & 总 & $\frac{\mathbb{Z}}{\Sigma}$ & 急 & $\frac{\stackrel{m}{N}}{N}$ & $\vec{\Xi}$ & 商 & 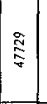 & $\stackrel{\circ}{\Xi}$ & 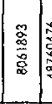 & 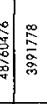 & 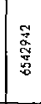 & 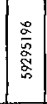 & 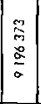 & \begin{tabular}{|l}
$x$ \\
0 \\
0 \\
0 \\
0 \\
0 \\
0
\end{tabular} & $\begin{array}{l}\text { 韵 } \\
\text { : } \\
\text { : }\end{array}$ & $\frac{\frac{3}{8}}{\frac{3}{5}}$ & 言 & 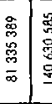 & $\begin{array}{ll}3 \\
3 \\
3\end{array}$ & \\
\hline$\frac{a}{3}$ & & & $\stackrel{\sharp}{*}$ & $\stackrel{\mathscr{g}}{\underline{\pi}}$ & $\underline{a}$ & 管 & $\mid$ & $\mathscr{F}$ & 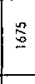 & 总 & 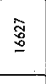 & 总 & 䁹 & $\stackrel{\mathscr{:}}{\mathscr{8}}$ & 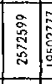 & 塎高 & 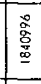 & 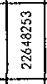 & \begin{tabular}{|c|} 
\\
\\
0 \\
3 \\
\\
\\
\end{tabular} & \begin{tabular}{|c|}
0 \\
0 \\
0 \\
0 \\
0 \\
0 \\
0
\end{tabular} & \begin{tabular}{|l}
$\frac{1}{2}$ \\
$\frac{\sigma}{\sigma}$ \\
$\bar{\alpha}$ \\
\end{tabular} & 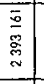 & 咅 & 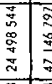 & \begin{tabular}{|ll} 
\\
\hdashline \\
\hdashline
\end{tabular} & \\
\hline 彦 & & & 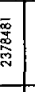 & $\begin{array}{l}\overline{\bar{s}} \\
\stackrel{9}{\cong}\end{array}$ & ڤั & 商 & $\frac{2}{2}$ & 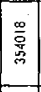 & 獸 & 紊 & $\begin{array}{l}\stackrel{\ddot{*}}{=} \\
=\end{array}$ & 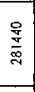 & 管 & 害 & 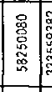 & 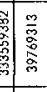 & 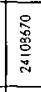 & 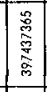 & 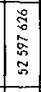 & 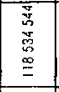 & 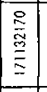 & $\begin{array}{l}\frac{0}{0} \\
\frac{f}{y}\end{array}$ & \begin{tabular}{|l}
0 \\
\\
\end{tabular} & 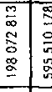 & 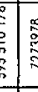 & \\
\hline 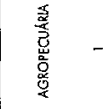 & 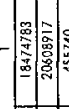 & & & 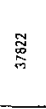 & $\frac{9}{7}$ & $\frac{\text { 量 }}{\underline{9}}$ & \% & 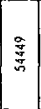 & 翌 & 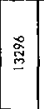 & జ్జ & 产 & 总 & $\stackrel{\stackrel{\Xi}{\bar{\omega}}}{ }$ & 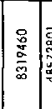 & 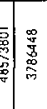 & 总 & 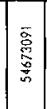 & 竧 & 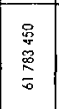 & 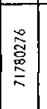 & $\stackrel{\frac{9}{2}}{\sim}$ & 递 & 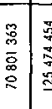 & 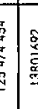 & \\
\hline 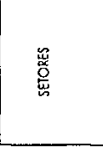 & 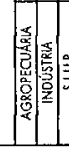 & 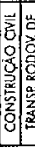 & & . & & & & & & & 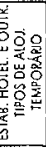 & & & 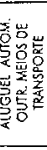 & 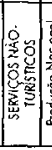 & 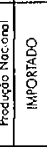 & . & $\mid$ & 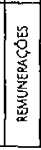 & 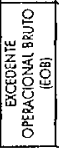 & 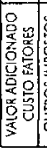 & $\mid$ & \begin{tabular}{|l|l}
$x$ & \\
\\
0
\end{tabular} & \begin{tabular}{l|l}
0 & 0 \\
0 \\
0
\end{tabular} & \begin{tabular}{|ll}
2 \\
2 \\
2
\end{tabular} & \\
\hline
\end{tabular}

Fonte: Casimiro Filho (2002). 
Tabela A1: Matriz de insumo-produto agregada nos setores para economia turística, Brasil, 1999 (valores correntes em $1.000 \mathrm{R} \$$ )

\begin{tabular}{|c|c|c|c|c|c|c|c|c|c|c|c|c|c|c|c|c|c|c|c|c|c|c|c|c|}
\hline 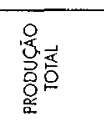 & 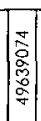 & 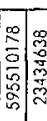 & & 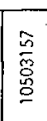 & $\begin{array}{l}\infty \\
0 \\
0 \\
0 \\
0\end{array}$ & $\overline{\mathrm{s}}$ & 竎 & & & & $\begin{array}{c}\text { o. } \\
\text { o. } \\
\text { o. } \\
\text { s. }\end{array}$ & 交 & 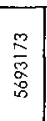 & 商 & & 幽: & 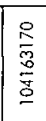 & 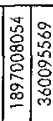 & 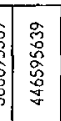 & 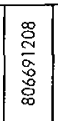 & $\begin{array}{l}\text { 总 } \\
\hat{0} \\
\frac{0}{3}\end{array}$ & 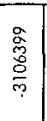 & \begin{tabular}{|l}
0 \\
0 \\
0 \\
0 \\
0 \\
0 \\
0 \\
$\infty$ \\
$\infty$
\end{tabular} & 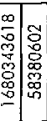 \\
\hline  & Ev & 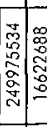 & & 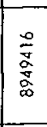 & 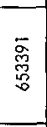 & 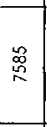 & 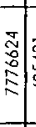 & & & & 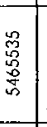 & 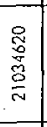 & 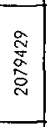 & 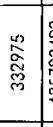 & 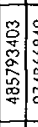 & $=0$ & 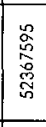 & $\left|\begin{array}{c}0 \\
\vdots \\
0 \\
0 \\
0 \\
0 \\
\vdots \\
\vdots\end{array}\right|$ & 0 & 0 & 0 & 0 & 0 & \\
\hline 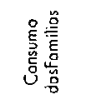 & $\mid \begin{array}{c}\frac{m}{a} \\
\frac{a}{a} \\
\frac{a}{w} \\
\end{array}$ & 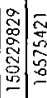 & & 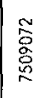 & 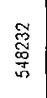 & 㕝 & 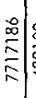 & & & & 芯 & 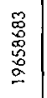 & 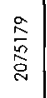 & 芯 & & 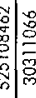 & 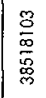 & $\left|\begin{array}{c}- \\
0 \\
0 \\
0 \\
0 \\
0 \\
\vdots \\
\vdots \\
\vdots\end{array}\right|$ & 0 & 0 & 0 & 0 & 0 & \\
\hline 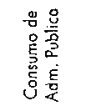 & 0 & 100 & 10 & 0 & $\circ$ & $\circ$ & 0 & 0 & 1 & 0 & 0 & 0 & 0 & 0 & 1 & 810 & 0 & $\left|\begin{array}{l}0 \\
0 \\
0 \\
0 \\
0 \\
0\end{array}\right|$ & 0 & 0 & 0 & 0 & 0 & \\
\hline 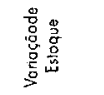 & {$\left[\begin{array}{l}n \\
\vdots \\
0\end{array}\right]$} & 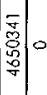 & & $\mid \begin{array}{c}\frac{a}{8} \\
\frac{5}{6}\end{array}$ & 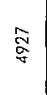 & is & 品 & 四) & & 商 & $\cong$ & $\ddot{0}$ & $\stackrel{-\sigma}{m}$ & 品 & $\infty$ & 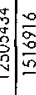 & $\stackrel{ }{\stackrel{0}{0}}$ & $\left|\begin{array}{l}0 \\
0 \\
0 \\
0 \\
0 \\
0 \\
0\end{array}\right|$ & a & 0 & 0 & 0 & 0 & 10 \\
\hline $\begin{array}{l}\text { 总 } \\
\text { on } \\
\text { 总 } \\
\text { 总 }\end{array}$ & 总 & & $\frac{0}{2}=0$ & 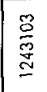 & 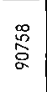 & $\begin{array}{l}\overrightarrow{8} \\
\stackrel{0}{2}\end{array}$ & 畄. & 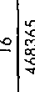 & 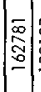 & & 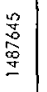 & 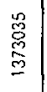 & 总 & 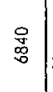 & 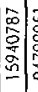 & $\circ$ & 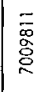 & $\left|\begin{array}{c}\mathbf{9} \\
0 \\
0 \\
0 \\
\vdots \\
0\end{array}\right|$ & 0 & 0 & $\circ$ & 0 & 0 & \\
\hline 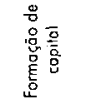 & \begin{tabular}{|l|} 
\\
0 \\
0 \\
0 \\
0
\end{tabular} & 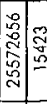 & & 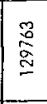 & 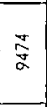 & $\stackrel{9}{\cong}$ & $\infty$ & $\sim \infty$ & 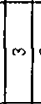 & $\sim$ & 品 & 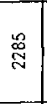 & 忿 & $\underset{ \pm}{\Psi}$ & 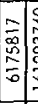 & 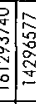 & 范 & 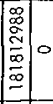 & 0 & $\circ$ & 0 & 0 & 10 & 10 \\
\hline 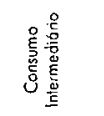 & 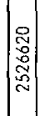 & 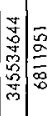 & & 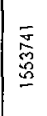 & 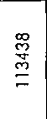 & 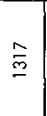 & 商 & 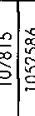 & $\begin{array}{l}0 \\
0 \\
0 \\
\text { pen }\end{array}$ & & $\begin{array}{l}\overline{\bar{g}} \\
\stackrel{\bar{m}}{\mathrm{~m}}\end{array}$ & 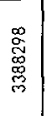 & $\begin{array}{l}\frac{\pi}{0} \\
\frac{m}{0} \\
\frac{0}{0}\end{array}$ & 䒿 & 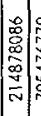 & $\begin{array}{l}0 \\
0 \\
0 \\
0\end{array}$ & 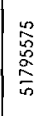 & 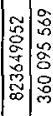 & \begin{tabular}{|l|}
0 \\
0 \\
0
\end{tabular} & 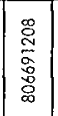 & 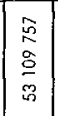 & $\begin{array}{c}\text { 总 } \\
\stackrel{8}{\circ} \\
\frac{0}{9}\end{array}$ & 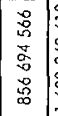 & 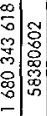 \\
\hline 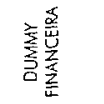 & 0 & & 10 & 0 & 0 & 0 & 10 & 0.0 & 0 & & 0 & 0 & 0 & 0 & I & 0 & 0 & 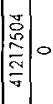 & 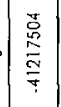 & 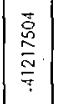 & 0 & 0 & 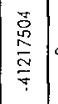 & \\
\hline 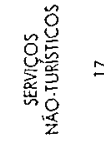 & d. & & & $\mid \begin{array}{l}\bar{z} \\
\bar{\sigma} \\
\underline{\underline{0}}\end{array}$ & 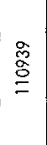 & 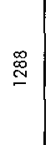 & 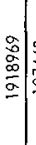 & 通 & & & 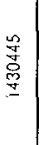 & 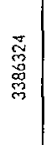 & $\begin{array}{l}0 \\
0 \\
\overline{0} \\
0\end{array}$ & 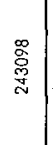 & $\mid \overline{\mathbf{D}}$ & 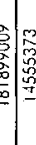 & 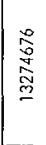 & 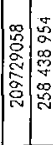 & 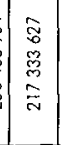 & 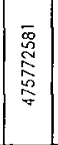 & $\begin{array}{l}7 \\
0 \\
0 \\
8 \\
o \\
0\end{array}$ & $\begin{array}{l}\bar{\alpha} \\
\stackrel{人}{\alpha}\end{array}$ & 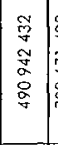 & 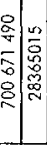 \\
\hline 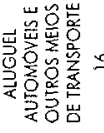 & 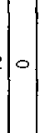 & & & $\approx$ & $\therefore$ & $r$ & $\mid$ & gof & $:$ & $\infty$ & 亭 & 莒 & 㫗 & $\stackrel{\infty}{\sim}$ & 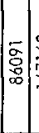 & : & $\begin{array}{l}\text { 卓 } \\
\underline{\Xi}\end{array}$ & | & 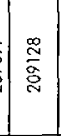 & 峁 & 今 & 0 & 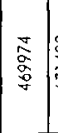 & \\
\hline 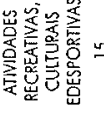 & 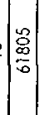 & & & 总 & 㩊 & $\stackrel{\infty}{\sim}$ & : & $\therefore$ & 희 & ळ & 总 & $\bar{\sigma}$ & 号 & 亏 & 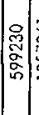 & 5 & 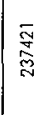 & 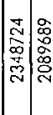 & 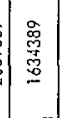 & 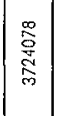 & $\begin{array}{l}\stackrel{\circ}{\circ} \\
\stackrel{0}{a} \\
=\end{array}$ & 0 & 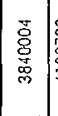 & \\
\hline 岕 & 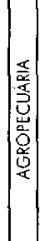 & 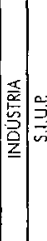 & 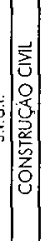 & 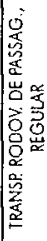 & 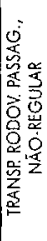 & 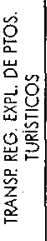 & 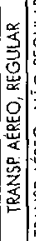 & 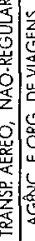 & 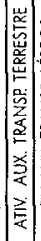 & & 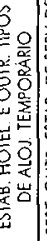 & 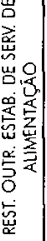 & 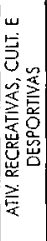 & 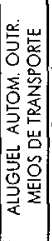 & $\mid$ & 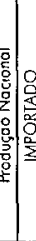 & 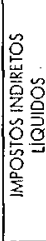 & 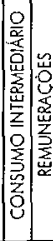 & 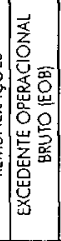 & 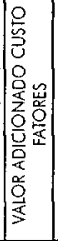 & 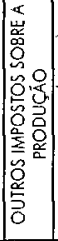 & 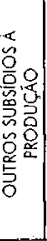 & 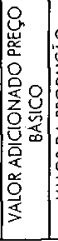 & 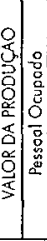 \\
\hline
\end{tabular}

